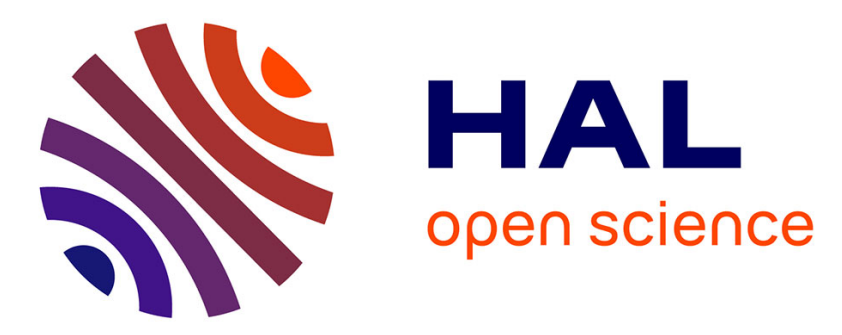

\title{
A density current parameterization coupled with Emanuel's convection scheme. Part II: 1D simulations
}

Jean-Yves Grandpeix, Jean-Philippe Lafore, Frédérique Cheruy

\section{To cite this version:}

Jean-Yves Grandpeix, Jean-Philippe Lafore, Frédérique Cheruy. A density current parameterization coupled with Emanuel's convection scheme. Part II: 1D simulations. Journal of the Atmospheric Sciences, 2010, 67 (4), pp.898-922. 10.1175/2009JAS3045.1 . hal-01135804

\author{
HAL Id: hal-01135804 \\ https://hal.science/hal-01135804
}

Submitted on 26 Mar 2015

HAL is a multi-disciplinary open access archive for the deposit and dissemination of scientific research documents, whether they are published or not. The documents may come from teaching and research institutions in France or abroad, or from public or private research centers.
L'archive ouverte pluridisciplinaire HAL, est destinée au dépôt et à la diffusion de documents scientifiques de niveau recherche, publiés ou non, émanant des établissements d'enseignement et de recherche français ou étrangers, des laboratoires publics ou privés. 


\title{
A Density Current Parameterization Coupled with Emanuel's Convection Scheme. Part II: 1D Simulations
}

\author{
JEAN-YVES GRANDPEIX \\ Laboratoire de Météorologie Dynamique, Paris, France \\ JEAN-PHILIPPE LAFORE \\ CNRM-GAME, Météo-France, and CNRS, Toulouse, France \\ FRÉDÉRIQUE CHERUY \\ Laboratoire de Météorologie Dynamique, Paris, France
}

(Manuscript received 22 December 2008, in final form 10 November 2009)

\begin{abstract}
The density current parameterization coupled with Emanuel's convection scheme, described in Part I of this series of papers, is tested in a single-column framework for continental and maritime convective systems. The case definitions and reference simulations are provided by cloud-resolving models (CRMs). For both cases, the wake scheme yields cold pools with temperature and humidity differences relative to the environment in reasonable agreement with observations (with wake depth on the order of $2 \mathrm{~km}$ over land and $1 \mathrm{~km}$ over ocean). The coupling with the convection scheme yields convective heating, drying, and precipitation similar to those simulated by the CRM. Thus, the representation of the action of the wakes on convection in terms of available lifting energy (ALE) and available lifting power (ALP) appears satisfactory. The sensitivity of the wake-convection system to the basic parameters of the parameterization is widely explored. A range of values for each parameter is recommended to help with implementing the scheme in a full-fledged general circulation model.
\end{abstract}

\section{Introduction}

As reviewed in the introduction of the first part of this series of papers (Grandpeix and Lafore 2010, hereafter Part I), density currents generated by precipitation-driven downdrafts are recognized as a key feature of moist convection. The density currents inhibit convection in the zone where they spread (cold pool) but allow new convection to be triggered on their leading edges. This phenomenon is present in a variety of convective systems including individual thunderstorms, organized convection, and propagating and nonpropagating convection (e.g., Gaynor and Mandics 1978). The density currents impact the life cycle of the convective activity-triggering, duration, and diurnal cycle (e.g., Piriou et al. 2007; Rio et al.

Corresponding author address: J.-Y. Grandpeix, Laboratoire de Météorologie Dynamique, Boite 99, 4, Place Jussieu, F-75252, Paris CEDEX 05, France.

E-mail: jyg@lmd.jussieu.fr
2009) — and can affect its organization and the propagation of the convective systems. By modifying the boundary layer conditions, they also affect surface fluxes and earthatmosphere energy exchanges (e.g., Young et al. 1995).

For general circulation models (GCMs), such a salient footprint of convection, hereafter called a wake, is an important subgrid-scale feature whose inclusion in parameterizations should be beneficial. To our knowledge, the Qian scheme (Qian et al. 1998; Rozbicki et al. 1999) is the only previous attempt to represent convective wakes in GCMs.

In the first part of this series of papers, a new parameterization of the wake, its coupling with Emanuel's convection scheme (Emanuel 1991, 1993; KE scheme hereafter), and a new trigger function and closure were presented. The last two account for the role played in deep convection development by several lifting processes (orographic lifting, wakes, land-sea contrasts, etc.). This second part reports their preliminary evaluation and illustrates the improvements they provide. 
Analyzing the performance of a new parameterization is a process that goes back and forth many times between the development of the parameterization on academic cases, preliminary tests on realistic cases, and full 3D implementation allowing the global GCM to be validated. Here we deal with an intermediate evaluation step. At this stage, the intention is to verify that the behavior of the new parameterization is physically correct; for instance, that the simulated wake characteristics are realistic, the timing of the convection is satisfactory, the convection yields precipitation, the humidity fields are reasonable, and so on. A later step would concern the quantitative evaluation of the parameterization but is beyond the scope of the present paper. The full 3D implementation step is underway and the results will soon be presented (R. Roehrig and J.-Y. Grandpeix 2009, unpublished manuscript).

The wake model coupled with the Emanuel's scheme is tested in a single-column framework. The methodology is similar to the one used in the Global Energy and Water Cycle Experiment (GEWEX) Cloud System Study (GCSS) and in the European Project on Cloud Systems in Climate Models (EUROCS) (Redelsperger et al. 2000). It consists in comparing a single-column version of the set (or a subset) of physical parameterizations with results of explicit simulations of the same phenomenon by cloud-resolving models (CRMs). The advantage of this approach is that CRMs provide a detailed description of each relevant physical process whose impact can be isolated in order to consistently test components or the whole parameterization scheme. A number of diagnostic variables can be extracted from the explicit simulations, making it possible to identify which component of the parameterization is performing well or badly (e.g., Bechtold et al. 2000). The counterpart of this approach is that the explicit simulations are quite heavy, so the number of available cases is limited.

Here, the new parameterization is implemented using the single-column version of the GCM of the Laboratoire de Météorologie Dynamique with zoom capability (LMDZ GCM; Hourdin et al. 2006). It is mostly tested for the case of a continental squall line (SL) observed over the Sahel in West Africa. This case exhibits intense wakes, which play an essential role in the life cycle of the squall line. The sensitivity of the wakeconvection system to the basic parameters of the parameterization is widely explored. Its functioning and its interaction with the convection are analyzed through an extensive set of diagnostic variables. Simulations with and without the implementation of the wake parameterization show how the wake parameterization improves on the original convective parameterization. A range of values for each parameter is proposed in order to prepare the implementation of the parameterization in the full LMDZ 3D GCM. Because the parameterization is meant to be implemented in a GCM and has to work for all the possible situations, we also verify that it is applicable for the very different case of a maritime mesoscale convective system observed over the western Pacific warm pool, where the wake is much less intense. Also, Rio et al. (2009) used this parameterization in a 1D framework to simulate a case of shallow to deep continental convection transition observed over the southern Great Plains (United States) at the Atmospheric Radiation Measurement (ARM) site.

The paper is organized as follows: Section 2 summarizes the wake equations and their coupling with the KE scheme derived in detail in Part I. After a brief description of the case study and of the setup of the numerical experiments, section 3 details the results for the continental Sahelian squall line observed during the Hydrological Atmospheric Pilot Experiment (HAPEX) '92 field campaign. In section 4, special attention is given to analyzing the role of each process in shaping the wake temperature and vapor characteristics and their evolution, as well as its interplay with the convective scheme. Section 5 checks that the coupled wake and deep convection scheme can also simulate the case of a less intense wake associated with a maritime squall line observed during the Tropical Ocean Global Atmosphere Coupled Ocean-Atmosphere Response Experiment (TOGA COARE). Conclusions and further work are presented in section 6.

\section{The model and the numerical setup}

The interested reader is invited to refer to Part I for detailed derivations and physical discussions of the set of equations of the wake model and its coupling with the KE scheme, briefly summarized below.

\section{a. Summary of the wake model}

The model represents a population of circular cold pools (the wakes) with vertical frontiers over an infinite plane containing the grid cell. The wakes are cooled by the convective precipitating downdrafts, while the air outside the wakes feeds the convective saturated drafts.

The wakes are assumed to be identical (they have the same height $h_{w}$, radius $r$, and vertical profiles of thermodynamic variables) and their centers statistically distributed with a uniform spatial density $D_{\text {wk }}$. The wakes cover a fractional area $\sigma_{w}$ given by $\sigma_{w}=D_{\mathrm{wk}} \pi r^{2}$.

The energy and water vapor equations are expressed at each level using the potential temperature difference $\delta \theta(p)$, the specific humidity difference $\delta q_{v}(p)$, and the vertical velocity difference $\delta \omega(p)$ between the wake 
region $(w)$ and the off-wake region $(x)$, together with the average temperature $\bar{\theta}$, the average humidity $\overline{q_{v}}$, and the large-scale vertical velocity $\bar{\omega}$.

The wakes are cold and subside ( $\delta \theta$ is negative and $\delta \omega$ is positive) below the wake top, which is approximately the level $p_{w}$ (altitude $h_{w}$ ) where $\delta \theta$ crosses zero [a more robust definition of the wake top is given below; Eq. (3)]. Above the wake top, the temperature and humidity of regions $(w)$ and $(x)$ may differ up to the homogeneity level $p_{h}$ chosen arbitrarily equal to $0.6 p_{s}$ (where $p_{s}$ is the surface pressure).

The wake geometrical changes with time are due to the spread and the coalescence of the wakes. Coalescence is merely represented by an imposed behavior $D_{\mathrm{wk}}(t)$.

\section{1) SPREAding}

Wake air being denser than off-wake air, wakes spread as density currents. The mean spread speed $C_{*}$ of the wake leading edges is proportional to the square root of the wake potential energy (WAPE):

$$
C_{*}=k_{*} \sqrt{2 \mathrm{WAPE}},
$$

where $k_{*}$, the spread efficiency, is a tunable parameter in the range of $1 / 3$ to $2 / 3$ and

$$
\mathrm{WAPE}=-g \int_{0}^{h_{w}} \frac{\delta \theta_{v}}{\overline{\theta_{v}}} d z,
$$

where $\theta_{v}$ is the virtual potential temperature and the wake height $h_{w}$ is defined by

$$
\frac{1}{2} g h_{w} \frac{\delta \theta_{\min }}{\theta}=- \text { WAPE. }
$$

The growth rate of the wake fractional area $\sigma_{w}$ reads

$$
\partial_{t} \sigma_{w}=2 C_{*} \sqrt{\pi D_{\mathrm{wk}} \sigma_{w}} .
$$

\section{2) VERTICAL MOVEMENT AND WAKE LATERAL ENTRAINMENT}

The vertical profile of the vertical velocity difference $\delta \omega$ is related to the lateral entrainment $e_{w}$ into the wakes and to the lateral detrainment $d_{w}$ from the wakes. This relation depends on the spatial distribution of the wakes relative to the grid cell. A parameter $\eta$ is introduced to distinguish between two situations, namely (i) $\eta=1$ when wakes are distributed randomly relative to the grid cell, which is the case usually encountered in GCMs and also in the HAPEX case studied in section 3, and (ii) $\eta=$ 0 in the confined case (i.e., when the grid cell follows the convective system, so that wakes do not intersect the grid cell boundaries), which occurs in the TOGA case studied in section 5 .

In the present model, wakes are assumed free of detrainment at all levels.

Below wake top, the entrainment rate is assumed to be zero, which, since the wake cross section $\sigma_{w}$ is independent of $z$, imposes the vertical profile of the vertical velocity difference $\delta \omega$ :

$$
\begin{aligned}
\left(1-\sigma_{w}\right) \delta \omega(p) & =\left(p_{s}-p\right) \frac{\partial_{t} \sigma_{w}}{\sigma_{w}}-(1-\eta) \bar{\omega} \\
e_{w} & =0
\end{aligned}
$$

Above the homogeneity level, the difference $\delta \omega$ between average vertical velocities over the $w$ and $x$ regions is equal to the velocity difference $\delta \omega^{\mathrm{cv}}$ solely because of the convective draft mass fluxes (saturated drafts mass flux $M_{c}$ outside the wakes and precipitating downdrafts mass flux $M_{p}$ within the wakes): $\delta \omega^{\mathrm{cv}}=$ $-g\left[M_{p} / \sigma_{w}-M_{c} /\left(1-\sigma_{w}\right)\right]$. Since the two regions are alike, entrainment and detrainment are irrelevant.

Between wake top and homogeneity level, a linear profile is imposed for $\delta \omega$, from the value $\delta \omega_{w}$ given by Eq. (5) at $p=p_{w}$ to the value $\delta \omega_{h}=\delta \omega^{\mathrm{cv}}\left(p_{h}\right)$ at level $p_{h}$. Then, the entrainment $e_{w}$ is completely determined:

$$
\begin{aligned}
\delta \omega(p) & =\frac{\delta \omega_{h}-\delta \omega_{w}}{p_{w}-p_{h}}\left(p_{w}-p\right)+\delta \omega_{w}, \\
e_{w} & =\sigma_{w}\left(1-\sigma_{w}\right) \partial_{p} \delta \omega+\sigma_{w}(1-\eta) \partial_{p} \bar{\omega}+\partial_{t} \sigma_{w} .
\end{aligned}
$$

\section{3) Evolution EQuAtions OF THE THERMODYNAMICAL VARIABLES}

The combination of energy and mass budget equations for the regions $(w)$ and $(x)$ yields the following formulas for the evolution of $\bar{\theta}, \overline{q_{v}}, \delta \theta$, and $\delta q_{v}$ :

$$
\left\{\begin{array}{l}
\partial_{t} \bar{\theta}=\left(\partial_{t} \bar{\theta}\right)_{\mathrm{LS}}+\frac{Q_{R}+Q_{1}^{\mathrm{bl}}+Q_{1}^{\mathrm{cv}}+Q_{1}^{\mathrm{wk}}}{C_{p}} \\
\partial_{t} \overline{q_{v}}=\left(\partial_{t} \overline{q_{v}}\right)_{\mathrm{LS}}-\frac{Q_{2}^{\mathrm{bl}}+Q_{2}^{\mathrm{cv}}+Q_{2}^{\mathrm{wk}}}{L_{v}} \\
\frac{Q_{1}^{\mathrm{wk}}}{C_{p}}=+\left(\partial_{t} \sigma_{w}-e_{w}\right) \delta \theta-\sigma_{w}\left(1-\sigma_{w}\right) \delta \omega \partial_{p} \delta \theta \\
\frac{Q_{2}^{\mathrm{wk}}}{L_{v}}=-\left(\partial_{t} \sigma_{w}-e_{w}\right) \delta q_{v}+\sigma_{w}\left(1-\sigma_{w}\right) \delta \omega \partial_{p} \delta q_{v}
\end{array},\right.
$$

where $\left(\partial_{t} \bar{\theta}\right)_{\mathrm{LS}}\left[\left(\partial_{t} \overline{q_{v}}\right)_{\mathrm{LS}}\right]$ is the large-scale tendency of $\theta\left(q_{v}\right), Q_{R}$ is the radiative source, and $Q_{1}^{\mathrm{bl}}, Q_{1}^{\mathrm{cv}}$, 
$Q_{1}^{\mathrm{wk}}\left(Q_{2}^{\mathrm{bl}}, Q_{2}^{\mathrm{cv}}, Q_{2}^{\mathrm{wk}}\right)$ are the apparent heat sources (apparent moisture sinks) due to boundary layer, convection, and wake processes; $C_{p}$ is the heat capacity of dry air and $L_{v}$ is the latent heat of vaporization of water. Also,

$$
\left\{\begin{array}{c}
\partial_{t} \delta \theta=-\bar{\omega} \partial_{p} \delta \theta+\frac{\delta Q_{1}^{\mathrm{cv}}+\delta Q_{1}^{\mathrm{wk}}}{C_{p}}-\frac{k_{\mathrm{gw}}}{\tau_{\mathrm{gw}}} \delta \theta \\
\text { where } \tau_{\mathrm{gw}}=\frac{\sqrt{\sqrt{\sigma_{w}}\left(1-\sqrt{\sigma_{w}}\right)}}{4 N z \sqrt{D_{\mathrm{wk}}}} \\
\text { is the damping time by gravity waves } \\
\partial_{t} \delta q_{v}=-\bar{\omega} \partial_{p} \delta q_{v}-\frac{\delta Q_{2}^{\mathrm{cv}}+\delta Q_{2}^{\mathrm{wk}}}{L_{v}} \\
\frac{\delta Q_{1}^{\mathrm{wk}}}{C_{p}}=-\frac{e_{w}}{\sigma_{w}} \delta \theta-\delta \omega \partial_{p} \bar{\theta}-\left(1-2 \sigma_{w}\right) \delta \omega \partial_{p} \delta \theta \\
\frac{\delta Q_{2}^{\mathrm{wk}}}{L_{v}}=\frac{e_{w}}{\sigma_{w}} \delta q_{v}+\delta \omega \partial_{p} \overline{q_{v}}+\left(1-2 \sigma_{w}\right) \delta \omega \partial_{p} \delta q_{v}
\end{array}\right.
$$

where $N$ is the Brunt-Väisälä frequency and $z$ the altitude; $\delta Q_{1}^{\mathrm{cv}}$ and $\delta Q_{1}^{\mathrm{wk}}\left(\delta Q_{2}^{\mathrm{cv}}\right.$ and $\left.\delta Q_{2}^{\mathrm{wk}}\right)$ are the differential heat sources (moisture sinks) due to convection (presented at the end of the following subsection) and wakes; and $k_{\mathrm{gw}}$, the gravity wave efficiency, is a tunable parameter.

\section{b. Summary of the wake-convection coupling}

\section{1) ACTION OF WAKES ON CONVECTION}

The occurrence and intensity of convection depend on two interface variables: the available lifting energy (ALE) and the available lifting power (ALP).

\section{(i) Trigger}

ALE is the maximum kinetic energy that updrafts induced by subcloud processes may reach at the lifted condensation level (LCL). Convection occurs when ALE exceeds the convective inhibition (CIN). The ALE provided by wakes is equal to the WAPE.

\section{(ii) Closure}

ALP is the flux of kinetic energy associated with subcloud updrafts. It provides the power consumed in the convective updrafts to overcome inhibition and by dissipation. The ALP provided by wakes is $\widehat{P_{\text {lift }}^{\mathrm{wk}} \text { : }}$

$$
\widetilde{P_{\text {lift }}^{\mathrm{wk}}}=\mathcal{E}_{\text {lift }}^{\mathrm{wk}} \frac{1}{2} \rho C_{*}^{3} h_{w} \widetilde{L_{\Gamma}},
$$

where $\mathcal{E}_{\text {lift }}^{\mathrm{wk}}$, the lifting efficiency of the wakes, is a tunable parameter and $\widetilde{L_{\Gamma}}$ is the expectation value of the gust front length conditioned on the presence of some gust front within the grid box. A crude approximation is used for $\widetilde{L_{\Gamma}}$ :

$$
\widetilde{L_{\Gamma}}=\sqrt{\frac{\min \left(4 \pi^{2} r^{2}, S_{t}\right)}{\min \left[\frac{1}{\left(D_{\mathrm{wk}} S_{t}\right)^{2}}, 1\right]}},
$$

where $S_{t}$ is the total grid box area.

The closure relation reads

$$
M=\frac{\widetilde{P_{\text {lift }}^{\mathrm{wk}}}}{2 w_{B}^{2}-W_{\text {buoy }}},
$$

where

$$
W_{\text {buoy }}=\int_{z_{\mathrm{LCL}}}^{z_{\mathrm{LFC}}} g \frac{\theta_{v, u}-\overline{\theta_{v, x}}}{\overline{\theta_{v, x}}} d z
$$

is the part of the convective inhibition occurring between the LCL and the level of free convection (LFC).

The standard KE scheme closure provides the cloud mass flux $M_{0}$ and the tendencies $\left(\partial_{t} T\right)_{\mathrm{cv}, 0}(z),\left(\partial_{t} q_{v}\right)_{\mathrm{cv}, 0}(z)$ corresponding to a given fractional area of precipitating downdrafts $\sigma_{d, 0}=0.01$. The tendencies and downdraft area corresponding to the cloud-base mass flux given by the ALP closure are obtained by scaling:

$$
\left(\partial_{t} T\right)_{\mathrm{cv}}(z)=\frac{M}{M_{0}}\left(\partial_{t} T\right)_{\mathrm{cv}, 0}(z) \cdots \sigma_{d}=\frac{M}{M_{0}} \sigma_{d, 0}
$$

\section{(iii) The dual environment seen by convection}

The convective saturated drafts are located outside the wakes and meet the temperature and humidity profiles $\overline{\theta_{x}}$ and $\overline{q_{v x}}$, whereas the precipitating downdrafts meet the $\overline{\theta_{w}}$ and $\overline{q_{v w}}$ profiles:

$$
\begin{aligned}
& \overline{\theta_{w}}=\bar{\theta}+\left(1-\sigma_{w}\right) \delta \theta, \\
& \overline{\theta_{x}}=\bar{\theta}-\sigma_{w} \delta \theta .
\end{aligned}
$$

The CIN and convective available potential energy (CAPE) associated with the $\overline{\theta_{x}}$ and $\overline{q_{v x}}$ profiles will be denoted $\mathrm{CIN}_{x}$ and $\mathrm{CAPE}_{x}$.

\section{2) ACTION OF CONVECTION ON WAKES}

The convective scheme provides, on the one hand, the apparent heat source $Q_{1}^{\mathrm{cv}}$ and moisture sink $Q_{2}^{\mathrm{cv}}$, which act on the large-scale variables, and, on the other hand, the differential heat source $\delta Q_{1}^{\mathrm{cv}}$ and moisture sink $\delta Q_{2}^{\mathrm{cv}}$ feeding the wakes. In terms of the apparent heat sources (moisture sinks) due to saturated drafts $Q_{1}^{\mathrm{cv}, \mathrm{sat}}\left(Q_{2}^{\mathrm{cv}, \mathrm{sat}}\right)$ and to unsaturated drafts $Q_{1}^{\mathrm{cv}, \text { unsat }}\left(Q_{2}^{\mathrm{cv}, \text { unsat }}\right)$, the convective sources and sinks read 


$$
\left\{\begin{array}{l}
Q_{1}^{\mathrm{cv}}=Q_{1}^{\mathrm{cv}, \text { unsat }}+Q_{1}^{\mathrm{cv}, \mathrm{sat}} \\
\delta Q_{1}^{\mathrm{cv}}=\frac{Q_{1}^{\mathrm{cv}, \mathrm{unsat}}}{\sigma_{w}}-\frac{Q_{1}^{\mathrm{cv}, \mathrm{sat}}}{1-\sigma_{w}} \\
Q_{2}^{\mathrm{cv}}=Q_{2}^{\mathrm{cv}, \text { unsat }}+Q_{2}^{\mathrm{cv}, \mathrm{sat}} \\
\delta Q_{2}^{\mathrm{cv}}=\frac{Q_{2}^{\mathrm{cv}, \text { unsat }}}{\sigma_{w}}-\frac{Q_{2}^{\mathrm{cv}, \text { sat }}}{1-\sigma_{w}}
\end{array} .\right.
$$

\section{c. Implementation of the wake model}

Equations (7) and (8) are discretized on the model vertical grid (a staggered grid being used for $\delta \omega$ ). An upstream scheme is used for the vertical advection terms. This is straightforward for the advection by $\bar{\omega}$ in Eqs. (8). However, this is not the case for the advection by $\delta \omega$ in Eqs. (7) and (8), because the advection of $\delta \theta$ and $\delta q_{v}$ is coupled with the advection of $\bar{\theta}$ and $\overline{q_{v}}$, respectively, so the advection matrix has to be diagonalized prior to application of the upstream scheme.

An explicit Euler scheme is used for the time advance. Time splitting is necessary to verify the Courant-FriedrichLevy criterion for the advection by $\delta \omega$.

\section{Continental convection: The HAPEX92 case}

\section{a. Case description}

Redelsperger et al. (2002) provided a multiscale description of the 21 August 1992 weather system observed during the HAPEX-Sahel experiment conducted in Niger (Goutorbe et al. 1994). This long-lasting convective system developed around midday over the Air Mountains. The system quickly reached its mature stage, resembling an arc-shaped squall line moving at about $17 \mathrm{~m} \mathrm{~s}^{-1}$. The system passed over the HAPEX-Sahel network in the evening and started to decay around 0300 local time (LT) on 22 August, thus providing a finescale description of the system and of its associated wake (8-K drop at Niamey). The interested reader should refer to Redelsperger et al. (2002) for further details.

Diongue et al. (2002) realistically simulated the full life cycle of this Sahelian squall line with the two-way interactive grid-nested mesoscale nonhydrostatic atmospheric model (Méso-NH; Lafore et al. 1998) allowing an explicit resolution of deep convective cells. As illustrated by their Fig. 7, the model reproduces the onset of the SL over the Airr Mountains around noon: first, rain showers generate small cold pools by evaporation, which spread downslope. Their gradual merging contributes to the formation of an intense, deep, and widespread wake (200 km, 9-K drop) $3 \mathrm{~h}$ later associated with a southwestward fast-moving SL $\left(15 \mathrm{~m} \mathrm{~s}^{-1}\right)$ reaching Niamey in the evening. Thanks to the in-line budget diagnostic tools provided by Méso-NH, heat, moisture, and horizontal momentum full budgets (Lafore et al. 1998) were computed at a frequency of once per hour for different locations averaged over 200- and 300-kmsquare boxes. To test the coupled wake and deep convection schemes intensively, we decided to focus on the triggering stage of the SL over Aïr. The mature stage, involving the arrival in the grid box of an already formed SL with its wake, was considered too complicated a configuration for a first test of the coupled parameterizations.

\section{b. Setup of experiments}

Following the approach used in GCSS and in the European Cloud-Resolving Modeling Programme (EUCREM; Bechtold et al. 2000), the present single-column model (KE scheme coupled with the wake model) was initialized and forced according to the domain-averaged initial temperature and humidity profiles and with the heat and moisture budgets provided by a Méso-NH simulation of the Diongue et al. (2002) case. This simulation provided budgets for a $300 \times 300 \mathrm{~km}^{2}$ box centered around the Airr Mountains (called the grid box hereafter) between 1000 and 2000 LT. The SCM was forced by advection terms at scales larger than the grid box. Also, the effects of the surface fluxes and of the turbulent transport on the temperature and water vapor were prescribed in order to study the interplay between deep convection and wakes more specifically. The corresponding terms (the divergence of the eddy fluxes of temperature and humidity) shown in Fig. 1 were mainly confined to the planetary boundary layer (PBL). Up to $\simeq 1400 \mathrm{LT}$, a typical diurnal evolution of the PBL was observed, characterized by a fast deepening and warming together with an intense vertical redistribution of vapor, which dried and moistened the lower and upper PBL, respectively. This diurnal PBL evolution resulted in favorable conditions for the deep convection development around noon. The correct parameterization of such a PBL evolution is a crucial issue to improve the diurnal cycle of convection as shown by Rio et al. (2009), but it is outside the scope of the present paper. The forcing terms were extracted from budget computations every hour and linearly interpolated in between. The horizontal wind was not considered for the present experiments. Other conditions of the experiments are listed below.

- To represent the convection initiation over the Airr Mountains, forced contributions to ALE and ALP were provided: (i) $\mathrm{ALE}_{\text {oro }}=60 \mathrm{~J} \mathrm{~kg}^{-1}$; this value was chosen so that convection triggered rapidly after the beginning of the simulation. It is a realistic value for the kinetic energy of updrafts generated on sunlit mountain slopes; (ii) $\mathrm{ALP}_{\text {oro }}=0.1 \mathrm{~W} \mathrm{~m}^{-2}$ from 1000 to $1400 \mathrm{LT}$, decreasing linearly from 0.1 to 0.01 between 1400 and $1600 \mathrm{LT}$ and constant $\left(=0.01 \mathrm{~W} \mathrm{~m}^{-2}\right)$ till the end. The 

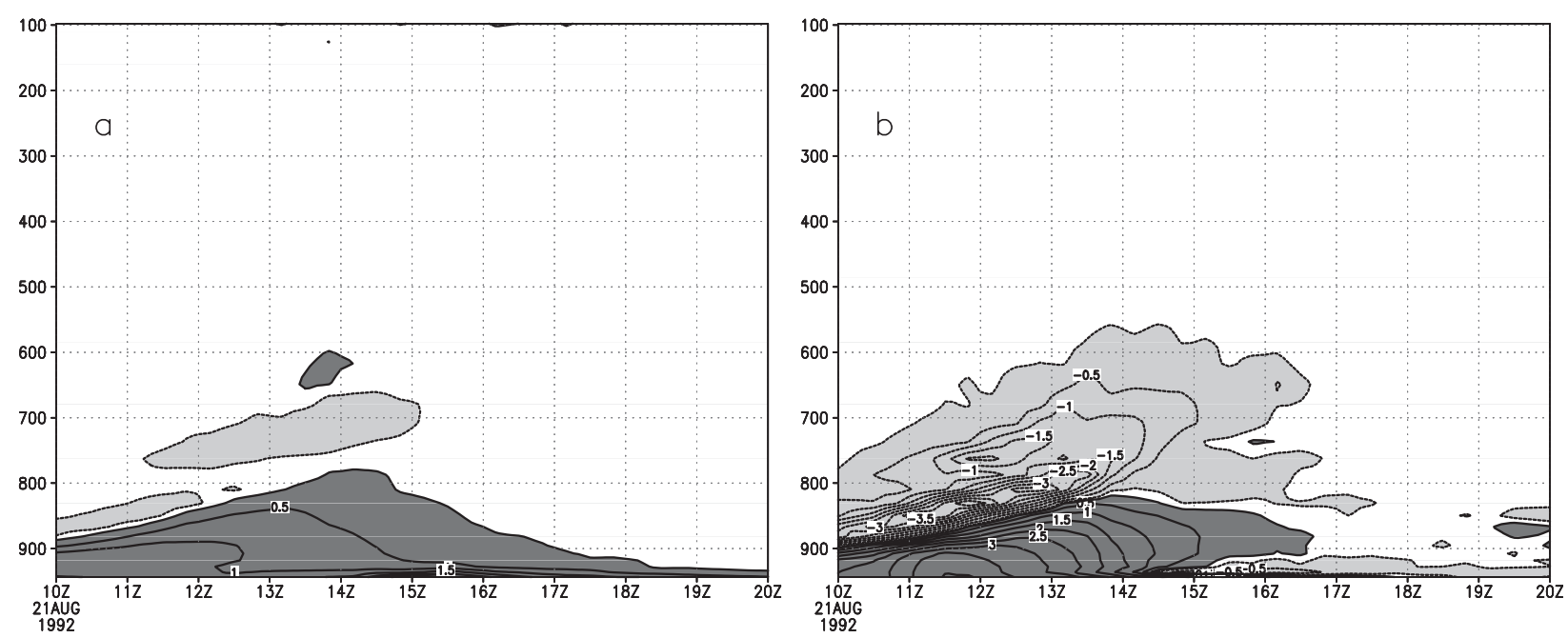

FIG. 1. HAPEX 92: 21 Aug squall line; prescribed (a) heat source $Q_{1}^{\mathrm{bl}} / C_{p}$ and (b) moisture sink $Q_{2}^{\mathrm{bl}} / C_{p}$ due to boundary layer processes $\left(\mathrm{K} \mathrm{h}^{-1}\right)$. Light gray and dark gray areas correspond to values below -0.1 and above $0.1 \mathrm{~K} \mathrm{~h}^{-1}$ respectively; contour spacing within these areas is $0.5 \mathrm{~K} \mathrm{~h}^{-1}$.

value $0.1 \mathrm{~W} \mathrm{~m}^{-2}$ is the value found in Rio et al. (2009) for the ALP provided by boundary layer thermals.

- The fractional area covered by wakes was kept constant once it reached 0.8 , so the problem of the wake life cycle was not dealt with.

- The change of the density of wakes, as simulated by the CRM, was represented by imposing a wake density decreasing exponentially from an initial value $D_{w 0}=$ $10^{-11} \mathrm{~m}^{-2}$ to a final value $D_{\mathrm{w} 1}=8 \times 10^{-12} \mathrm{~m}^{-2}$ with a relaxation time of $4 \mathrm{~h}$. It corresponds to the typical range of convective system densities observed over West Africa from satellite imagery (i.e., 10 to 1 convective systems within a $1000-\mathrm{km}$ square between the afternoon growing stage and the evening-night mature stage respectively.

The budgets of CRM simulations also provided interesting data allowing the evaluation of the SCM, in particular the evolution of the apparent heat source Q1 and moisture sink Q2, which will be extensively used in the following.

\section{c. The reference simulation}

The model depends on six parameters:

- the three efficiencies $k_{*}, \mathcal{E}_{\text {lift }}^{\mathrm{wk}}$, and $k_{\mathrm{gw}}$, for spread, wake lifting, and gravity damping terms, respectively;
- the wake density $D_{\mathrm{wk}}$;

- the convective updraft velocity $w_{B}$; and

- the precipitating downdraft cross section $\sigma_{d, 0}$.

The reference simulation (called REF hereafter) corresponds to the values listed in Table 1 . These values were chosen in order to obtain precipitation time series and $Q_{1}$ and $Q_{2}$ profiles in acceptable agreement with the Méso-NH simulation results (no fine tuning was attempted since it was expected that the tuning would eventually depend on the other parameterizations, especially the PBL one).

\section{1) WAKE BEHAVIOR}

CRM precipitation in the grid box (Fig. 2a) starts around 1100 LT and stays very weak and localized for $3 \mathrm{~h}$. Then the system becomes mature and precipitation increases to $2 \mathrm{~mm} \mathrm{~h}^{-1}$. Finally, it gradually stops after 1700 LT while the system moves southwestward out of the grid box. The REF simulation reproduces a similar scenario with a maximum that is a little more intense $\left(2.3\right.$ versus $\left.1.9 \mathrm{~mm} \mathrm{~h}^{-1}\right)$ and earlier by half an hour. Because of the PBL diurnal evolution and other forcing terms, the $\mathrm{CIN}_{x}$ decreases slowly and the convection scheme is triggered at $1140 \mathrm{LT}$, as soon as the $\mathrm{CIN}_{x}$ is overcome by the prescribed $\mathrm{ALE}_{\text {oro }}$ (Fig. 2d). Just after the convection onset, the wake model generates

TABLE 1. Parameter values and ranges for the two cases HAPEX and TOGA.

\begin{tabular}{lcccccc}
\hline \hline \multicolumn{1}{c}{ Parameter } & $k_{*}$ & $\mathcal{E}_{\text {lift }}^{\mathrm{wk}}$ & $k_{\mathrm{gw}}$ & $D_{\mathrm{wk}}\left(\mathrm{m}^{-2}\right)$ & $w_{B}\left(\mathrm{~m} \mathrm{~s}^{-1}\right)$ & $\sigma_{d, 0}$ \\
\hline Range & {$[0.25,0.65]$} & {$[0.2,0.4]$} & {$[0.5,2.5]$} & {$[1,10] \times 10^{-12}$} & {$[1,2]$} & {$[0.005,0.05]$} \\
Values for HAPEX & 0.33 & 0.25 & 1.0 & $10 \rightarrow 8 \times 10^{-12}$ & 2 & 0.01 \\
Values for TOGA & 0.53 & 0.25 & 1.0 & $4.0 \times 10^{-12}$ & 2 & 1 \\
\hline
\end{tabular}



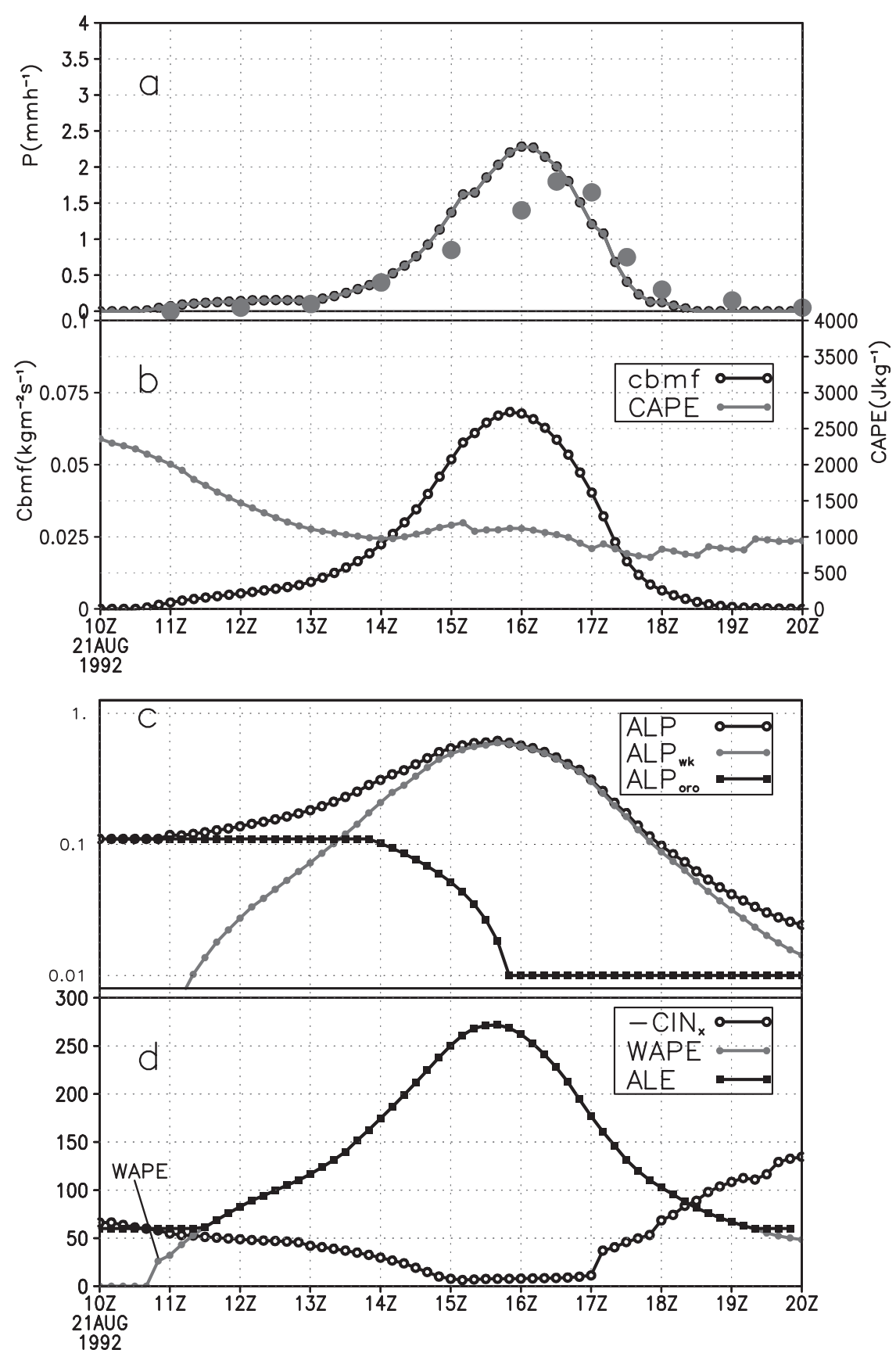

FIG. 2. HAPEX 92; 21 Aug squall line. (a) Precipitation $\left(\mathrm{mm} \mathrm{h}^{-1}\right)$ simulated by the SCM (convective $=$ black open circles; stratiform $=$ gray closed circles) and by the CRM (big gray dots). (b) Cloud-base mass flux $\left(\mathrm{kg} \mathrm{m}^{-2} \mathrm{~s}^{-1}\right.$, black open circles) and CAPE $\mathrm{C}_{x}\left(\mathrm{~J} \mathrm{~kg}^{-1}\right.$, gray closed squares). (c) ALP $\left(\mathrm{W} \mathrm{m}^{-2}\right)$ total (black open circles), ALP due to the wakes (gray closed squares), and forced ALP (black closed squares). (d) Evolution of the $\mathrm{CIN}_{x}\left(\mathrm{~J} \mathrm{~kg}^{-1}\right.$, black open circles), WAPE (gray closed circles), and ALE (black closed squares) simulated by the SCM.

a realistic cold pool as depicted by Fig. 3. After a rapid setup stabilizing its depth around $1300 \mathrm{~m}$, the wake evolves smoothly. It reaches its maximum intensity (9-K drop at surface and $1700-\mathrm{m}$ depth) at $1600 \mathrm{LT}$, in phase with the precipitation maximum and in agreement with observations, and decreases quickly thereafter. Wake spreading follows this evolution, resulting in an "exponential type" growth of the wake area $\sigma_{w}$ up to $1600 \mathrm{LT}$ and reaching 0.8 , the maximum allowed value, at 1800 LT. The vapor structure within the wake $\delta q_{v}$ (Fig. 3d) is 

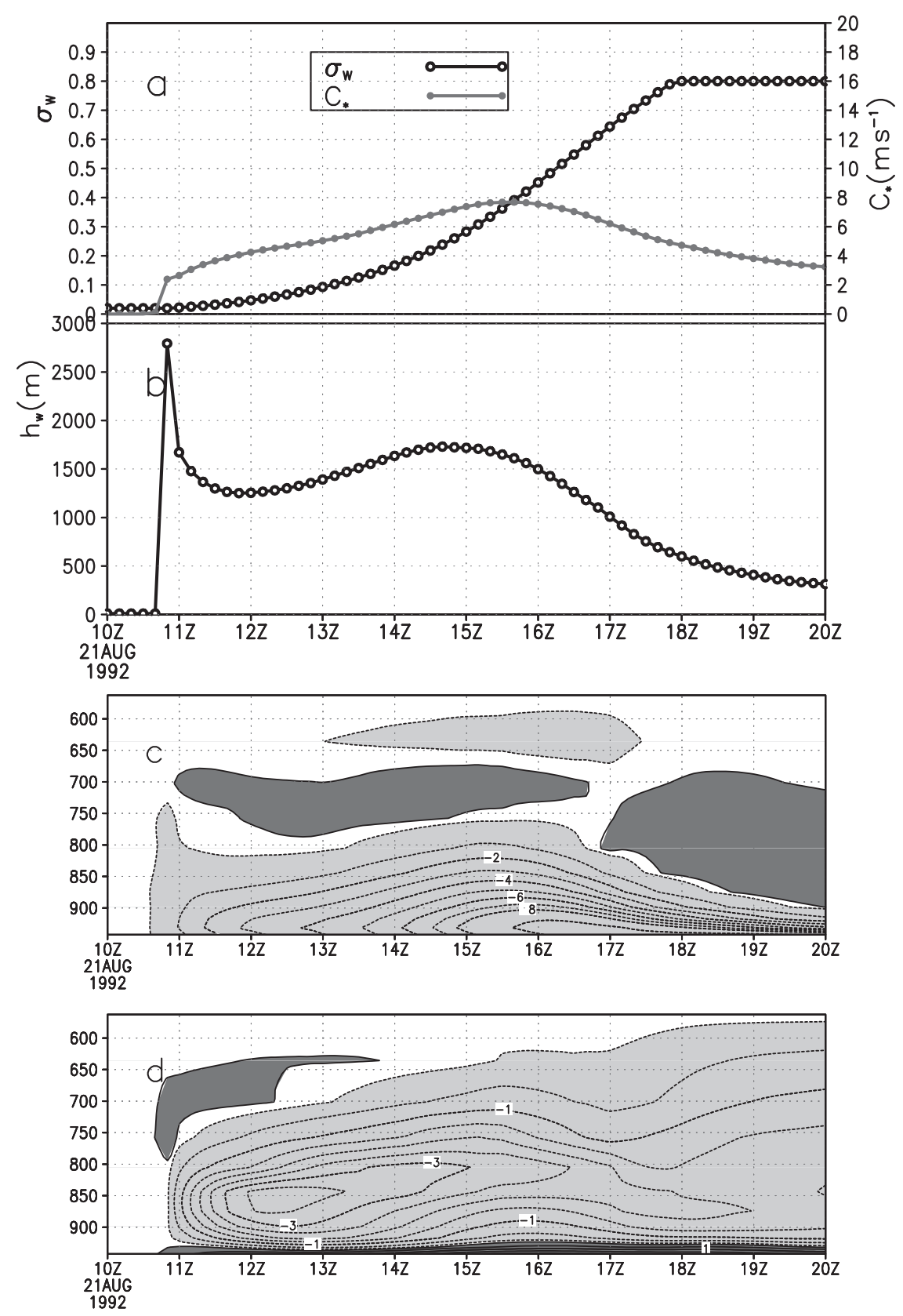

FIG. 3. HAPEX 92; 21 Aug squall line. (a) Wake fractional area $\sigma_{w}$ (black open circles) and spread velocity $C_{*}\left(\mathrm{~m} \mathrm{~s}^{-1}\right.$, gray closed circles), (b) wake height $h_{w}(\mathrm{~m})$, (c) $\delta \theta$ (light gray < $-0.1 \mathrm{~K} \mathrm{~h}^{-1}$; dark gray $>0.1 \mathrm{~K} \mathrm{~h}^{-1}$; contour spacing $=1 \mathrm{~K} \mathrm{~h}^{-1}$ ), and (d) $\delta q_{v}$ (light gray $<$ $-0.1 \mathrm{~g} \mathrm{~kg}^{-1} \mathrm{~h}^{-1}$; dark gray $>0.1 \mathrm{~g} \mathrm{~kg}^{-1} \mathrm{~h}^{-1}$; contour spacing $=0.5 \mathrm{~g} \mathrm{~kg}^{-1} \mathrm{~h}^{-1}$ ).

more complex than that of the temperature $\delta \theta$ (Fig. 3b). It consists of a "tongue" of dry air, maximum around 1300 $\mathrm{LT}\left(-3 \mathrm{~g} \mathrm{~kg}^{-1}\right)$ and centered around $850 \mathrm{hPa}$, whereas the temperature drop is maximum at the surface and decreases linearly to zero at the wake top $h_{w}$. While precipitation intensifies, the dry tongue weakens and elevates slowly by $50 \mathrm{hPa}$, giving rise to a thin layer of moisture close to the surface.

\section{2) WAKE FEEDBACK ON CONVECTION TRIGGERING AND INTENSITY}

Figure 2 gives an insight into the way the wake interacts with the convection scheme. Soon after convection onset, the wake provides enough energy $\mathrm{ALE}_{\mathrm{wk}}$ to overcome alone the $\mathrm{CIN}_{x}$ up to the simulation end without any orographic processes (Fig. 3d). It should be 

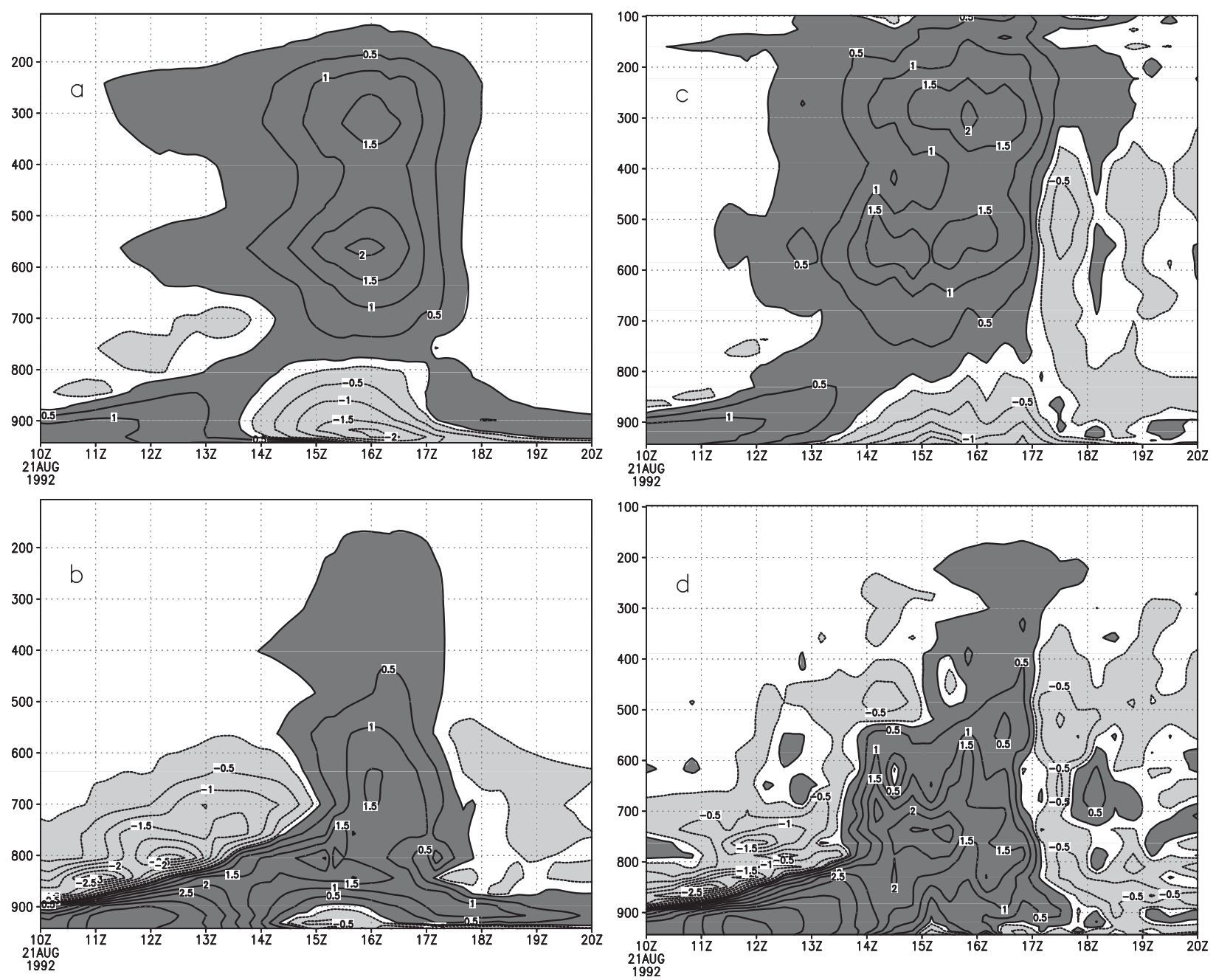

FIG. 4. HAPEX 92: 21 Aug squall line. (a),(c) Apparent heat source $Q_{1} / C_{p}$ simulated by the (a) SCM and (c) CRM; (b),(d) apparent moisture sink $Q_{2} / C_{p}$ simulated by the (b) SCM and (d) CRM. Light gray and dark gray areas correspond to values below -0.1 and above $0.1 \mathrm{~K} \mathrm{~h}^{-1}$, respectively; contour spacing within these areas is $0.5 \mathrm{~K} \mathrm{~h}^{-1}$.

noted that the inhibition seen by the convection $\left(\left|\mathrm{CIN}_{x}\right|\right)$ decreases down to values below $10 \mathrm{~J} \mathrm{~kg}^{-1}$ at $1500 \mathrm{LT}$. This low inhibition has two causes: (i) the compensating subsidence induced by convective updrafts is counteracted by the lifting induced in the off-wake region by the spreading of the wakes, and (ii) the low-level cooling induced by precipitating downdrafts is confined within the wakes, so it has no effect on the inhibition seen by convection. On the contrary, the inhibition at the gridbox scale increases (not shown) because of the stable stratification in the wake area. The precipitation (Fig. 2a) is directly determined by the convective cloud-base mass flux $M$ evolution (Fig. 2b), which is mainly governed by the lifting power provided by the wake $P_{\text {lift }}^{\mathrm{wk}}$ (Fig. 2c). Nevertheless, up to $1510 \mathrm{LT}$, the lifting power is dominated by orographic processes $\mathrm{ALP}_{\text {oro }}$ in agreement with the Aïr Mountain vicinity (Fig. 10 of Diongue et al.
2002). An analysis of the ALP diagnostic Eq. (9) using $C_{*}$ and $h_{w}$ expressions [Eqs. (1) and (3)] shows that $\mathrm{ALP}_{\mathrm{wk}}$ is proportional to $\mathrm{WAPE}^{5 / 2} \sigma_{w}^{1 / 2} / \delta \theta_{\min }$, so its evolution is more sensitive to the WAPE evolution than to that of $\sigma_{w}$. This sensitivity explains the rapid growth of the wake lifting power (Fig. 2c, logarithmic scale) around $1400 \mathrm{LT}$ due to the regular growth of the WAPE (Fig. 2d, linear scale), resulting in a rapid intensification of the convection mass flux and precipitation. We also conclude that a well-structured wake (deep, with intense WAPE) is more efficient at driving convection than a thinner wide one.

\section{3) IMPACT OF CONVECTION, WAKE, AND PBL PROCESSES $\left[Q_{1}(T)\right.$ AND $\left.Q_{2}(T)\right]$}

Figure 4 compares the variation of the vertical profiles of the apparent heat source $Q_{1}$ and moisture $\operatorname{sink} Q_{2}$ as 
simulated by the CRM and SCM models. Two successive stages are clearly visible, in which $Q_{1}$ and $Q_{2}$ are dominated by (i) PBL and shallow convection up to $1400 \mathrm{LT}$ and then by (ii) deep convection and wake processes up to 1700 LT. After 1700 LT, the deep convection decreases and leaves the grid box. The SCM reproduces these two stages quite well. During stage I, deep convection is localized over mountainous areas. The corresponding area of wakes $\sigma_{w}$ (Fig. 3b) and the convective mass flux $M$ (Fig. 2b) are still weak, so the apparent sources $Q_{1}$ and $Q_{2}$ are dominated by the PBL as confirmed by the similarities with the PBL forcing shown in Fig. 1. But this stage is crucial to the building of wakes: it increases their intensity (i.e., their WAPE) and total area.

Stage II corresponds to intense deep convection associated with the now well-structured squall line coupled with an intense wake. The SCM reproduces the structure and intensity of the $Q_{1}$ profile evolution characterized by a double-peak heating at 500 and $300 \mathrm{hPa}$ with similar maxima $\left(\simeq 2 \mathrm{~K} \mathrm{~h}^{-1}\right)$ and a cooling below $800 \mathrm{hPa}$, maximum at the surface, associated with the wake. For the moisture sink $Q_{2}$ profile, because of moisture transport by convective eddies (Lafore et al. 1988) the drying occurs at lower levels, with a $2.5 \mathrm{~K} \mathrm{~h}^{-1}$ maximum at $750 \mathrm{hPa}$ for the CRM. The SCM drying is a little weaker $\left(2 \mathrm{~K} \mathrm{~h}^{-1}\right)$ and lower $(800 \mathrm{hPa})$. Close to the surface, the thin moistening layer is reproduced by the SCM. We shall return to the improvements brought to the $Q_{2}$ profile by the coupled wake-convection scheme in paragraph 5 below.

\section{4) Budgets OF ENERGY AND WATER}

As first shown by Yanai et al. (1973), the apparent heat source $Q_{1}-Q_{R}$ integrated over the whole atmosphere depth is equal to the precipitation rate $P$ minus the surface sensible flux $F_{T}$, if the storage and export terms are negligible. To account for the transient part of convection and for the net lateral outflow of condensate, we must add the storage and export terms:

$\frac{1}{L_{v}} \int\left(Q_{1}-Q_{R}\right) \rho d z-\frac{1}{L_{v}} F_{T}=P+($ Storage and Export $)$.

Figure 5 compares the evolution of the left-hand side of this relation and of the precipitation $P$ for SCM and CRM simulations. The difference between the curves represents the storage and export of condensate. It is weak in the SCM simulation and of the same order of magnitude as the precipitation in the CRM simulation. It is a known defect of this SCM, as of many others, that not enough condensate is associated with deep convection (Fig. 7 of Bechtold et al. 2000). After 1700 LT, the precipitation decreases as the convection system is moving
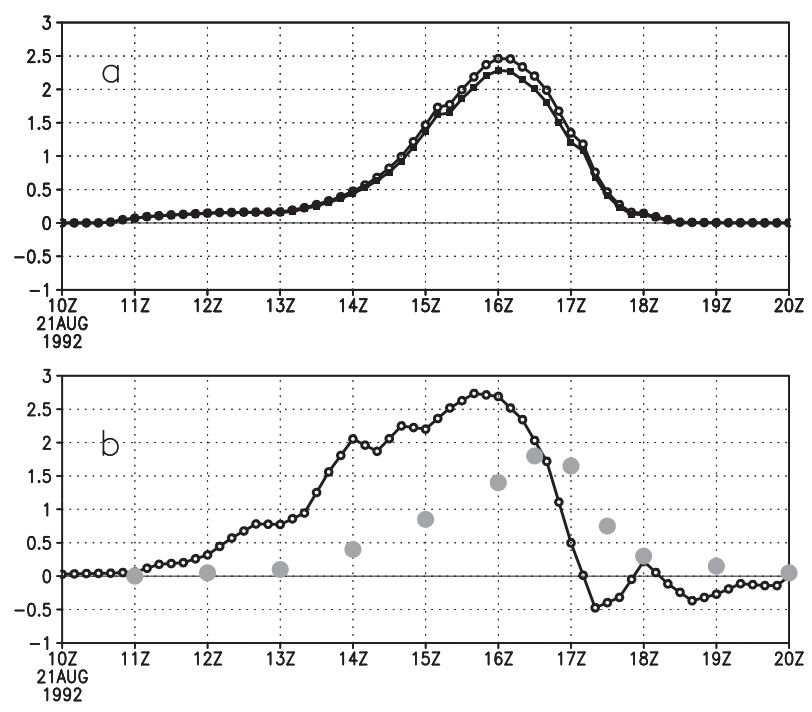

FIG. 5. HAPEX 92; 21 Aug squall line. (a) Condensate budget from $\left(1 / L_{v}\right) \int\left(Q_{1}-Q_{R}\right) \rho d z-F_{T} / L_{v}$, where $F_{T}$ is the surface sensible heat flux (black open circles); rain rate is represented by black closed squares. (b) As in (a) but for Méso-NH simulations, except that the rain rate is represented by big gray dots.

out of the grid box, so only the dissipating anvil stays behind. This dissipation stage is simulated by the CRM as the atmosphere cools and moistens because of condensate sublimation/evaporation as confirmed by negative profiles of $Q_{1}$ and $Q_{2}$ (Fig. 4). The SCM cannot reproduce such features because of the lack of condensate.

\section{5) BENEFIT OF THE WAKE PARAMETERIZATION}

It is legitimate to want to assess the improvements of the convection scheme due to its coupling with the wake model and to the simultaneous introduction of the ALE and ALP concepts to treat the triggering and closure of the convection scheme. To this end, Fig. 6 analyzes a series of four sensitivity experiments as compared with the CRM results. Table 2 summarizes the main characteristics of these sensitivity experiments. Experiment $\mathrm{E}$ corresponds to the standard KE scheme as implemented in the LMDZ GCM (Hourdin et al. 2006). Experiments AW and AS are intermediate sensitivity experiments between $E$ and REF simulations, testing only the impact of the introduction of ALE and ALP without the wake model. ALE is set at $60 \mathrm{~J} \mathrm{~kg}^{-1}$, corresponding to the initial value in REF, whereas ALP is set at weak and strong values $\left(0.1\right.$ and $\left.1.5 \mathrm{~W} \mathrm{~m}^{-2}\right)$ for the AW and AS experiments, respectively. The ALP weak value in AW corresponds to the minimum value prescribed in REF, whereas the strong value allows AS precipitation to reach the total amount simulated by the CRM.

Figure 6a shows the variation of precipitation in the four sensitivity experiments. As already shown by Fig. 2a, 

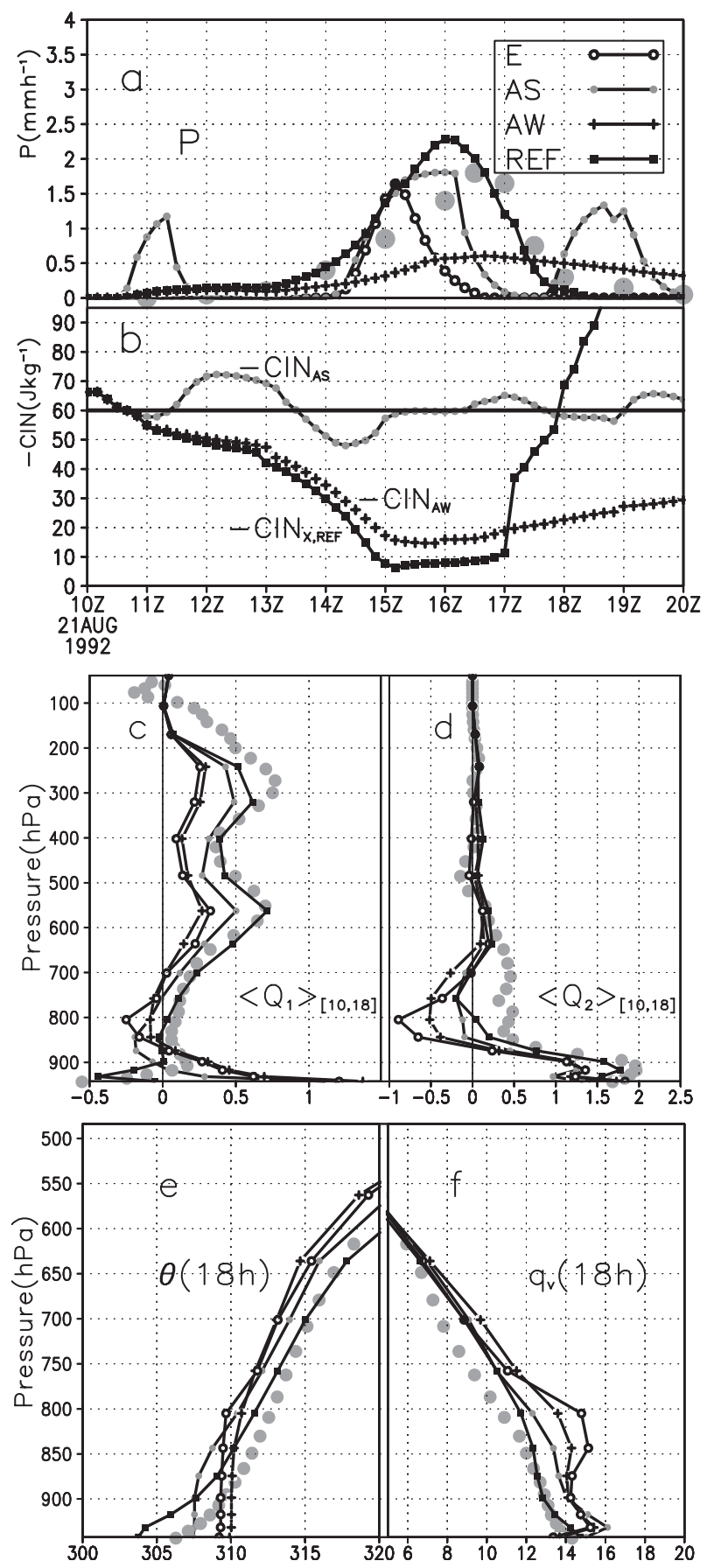

FIG. 6. HAPEX 92; 21 Aug squall line. (a),(b) Time series of (a) precipitation $\left(\mathrm{mm} \mathrm{h}^{-1}\right)$ and (b) CIN $\left(\mathrm{J} \mathrm{kg}^{-1}\right)$. (c),(d) Vertical profiles of average values between 1000 and $1800 \mathrm{LT}$ of (c) $Q_{1} / C_{p}$ and (d) $Q_{2} / C_{p}\left(\mathrm{~K} \mathrm{~h}^{-1}\right)$. (e),(f) Vertical profiles of (e) potential temperature $(\mathrm{K})$ and (f) humidity $\left(\mathrm{g} \mathrm{kg}^{-1}\right)$ at $1800 \mathrm{LT}$, from simulations E, AS, AW, and REF (curves with black open circles, gray closed circles, gray crosses, and black closed squares, respectively); Méso-NH results are superimposed (big gray dots).
REF reproduces the precipitation variation simulated by the CRM. The standard Emanuel convection scheme (E experiment) triggers a short-lived $(2 \mathrm{~h})$, moderate convection event at only $1420 \mathrm{LT}$ when the large-scale forcings induce low convective inhibition. The introduction of the ALE and ALP with prescribed values (AW and AS experiments) modifies the precipitation scenario depending on the ALP value. As expected, convection is triggered as soon as the convective inhibition (CIN in Fig. 6b) becomes weaker than ALE $\left(60 \mathrm{~J} \mathrm{~kg}^{-1}\right.$, heavy line). It first occurs at $1040 \mathrm{LT}$. Then the convective mass flux (and thus precipitation intensity) is governed by the ALP value as detailed in Eq. (33) of Part I. In consequence, for weak ALP value (AW experiment), the precipitation stays weak throughout the simulation, and the effect on CIN is small (recall that it is CIN, the convective inhibition at the gridbox scale, that is relevant in the AW and AS simulations, whereas it is $\mathrm{CIN}_{x}$ in $\mathrm{REF}$ ): before $1500 \mathrm{LT}$ the convective inhibition $|\mathrm{CIN}|$ decreases slowly because of the large-scale forcings, and after 1500 LT it increases gradually because of deep convection. In contrast, for strong ALP values (AS experiment), convection activity and precipitation increase quickly after their triggering, resulting in a strong increase of the CIN to values stronger than ALE so that the convection is switched off with a 20-min relaxation time (as stated in the convection scheme). Experiment AS exhibits three such burst precipitation events at 1020 , 1420, and 1800 LT. The second event has some similarities with the main peak simulated by the CRM although it occurs earlier because of the strong ALP value. Nevertheless, the other two peaks are not realistic. Only the REF simulation is able to reproduce the evolution pattern of precipitation thanks to the realistic evolution of ALP provided by the wake.

Figures $6 \mathrm{c}$ and $6 \mathrm{~d}$ analyze the impact of the different versions of the convection scheme by showing the profiles of apparent heat source and moisture sink after $8 \mathrm{~h}$ of simulation of this convective event. The REF simulation gives quite a good reproduction of the $Q_{1}$ and $Q_{2}$ profiles simulated by the CRM both for intensity and structure. Nevertheless, three deficiencies should be noted: a weak cooling $\left(-0.1 \mathrm{~K} \mathrm{~h}^{-1}\right)$ below $750 \mathrm{hPa}$ relative to the CRM, a lack of drying in the $850-600-\mathrm{hPa}$ layer, and a lack of penetration of the heating above $300 \mathrm{hPa}$. The last feature is not related to the introduction of wakes (REF). The other sensitivity experiments worked much less well, with too much cooling below $700 \mathrm{hPa}$ and a reinforcement of the moistening bias in the $850-750-\mathrm{hPa}$ layer. Convective heating is too weak in experiments $\mathrm{E}$ and $\mathrm{AW}$, whereas AS almost reaches the REF magnitude.

The resulting temperature and moisture profiles after $8 \mathrm{~h}$ of simulation (Figs. 6e,f) nicely illustrate the way the 
TABLE 2. The four simulations used to assess the roles of the wake model and of the control of the convective scheme by ALE and ALP.

\begin{tabular}{|c|c|c|c|c|}
\hline Simulation & Convection scheme & Wake scheme & $\operatorname{ALE}\left(\mathrm{J} \mathrm{kg}^{-1}\right)$ & $\operatorname{ALP}\left(\mathrm{W} \mathrm{m}^{-2}\right)$ \\
\hline E (Emanuel) & KE from Hourdin et al. (2006) & no & - & - \\
\hline AW (Alp weak) & Emanuel with ALE/ALP trigger/closure & no & 60.0 & 0.1 \\
\hline AS (Alp strong) & Emanuel with ALE/ALP trigger/closure & no & 60.0 & 1.5 \\
\hline REF (Reference) & Emanuel with ALE/ALP trigger/closure & yes & $\max (60.0$, WAPE $)$ & $0.1+\widetilde{P_{\mathrm{lift}}^{\mathrm{wk}}}$ \\
\hline
\end{tabular}

convection schemes perform. Only the REF experiment is able to reproduce the stable stratification at 1800 UTC after the convective event as simulated by the CRM. Because of a lack of deep convection, experiments $E$ and AW develop a deep, well-mixed PBL and a colder atmosphere above $-2 \mathrm{~K}$. Increasing the convective activity through ALP increase (AS experiment) reduces this defect but cannot generate the stable stratification at low levels because of the wake occurrence. We identify a major benefit of introducing the wake model here. Again concerning the moisture profile, REF works the best by drying much more than the others below $750 \mathrm{hPa}$. Nevertheless, as already detected on the $Q_{2}$ profile, there is still a deficit of drying in the 850-750-hPa layer.

In short, for this HAPEX-Sahel case study, the above analysis demonstrates that the standard Emanuel convection scheme is drastically improved by the introduction of the wake model and of ALE and ALP to treat the triggering and closure of the convection scheme. Only coupling with the wake model allows the atmosphere to be stabilized at low levels. Despite this improvement, there is still a deficit of drying in the $850-750-\mathrm{hPa}$ layer, which should be fixed in the future by better tuning of this new parameterization.

\section{Detailed analysis of the model performance}

This section aims to understand the wake workings and their impact on convection. It consists of an analysis of all the source terms of the prognostic wake variable [Eq. (8)] and of the mean variable [Eq. (7)]. The budgets will be analyzed at 1400 and 1600 LT, corresponding to the growth and mature stages of convection development, respectively.
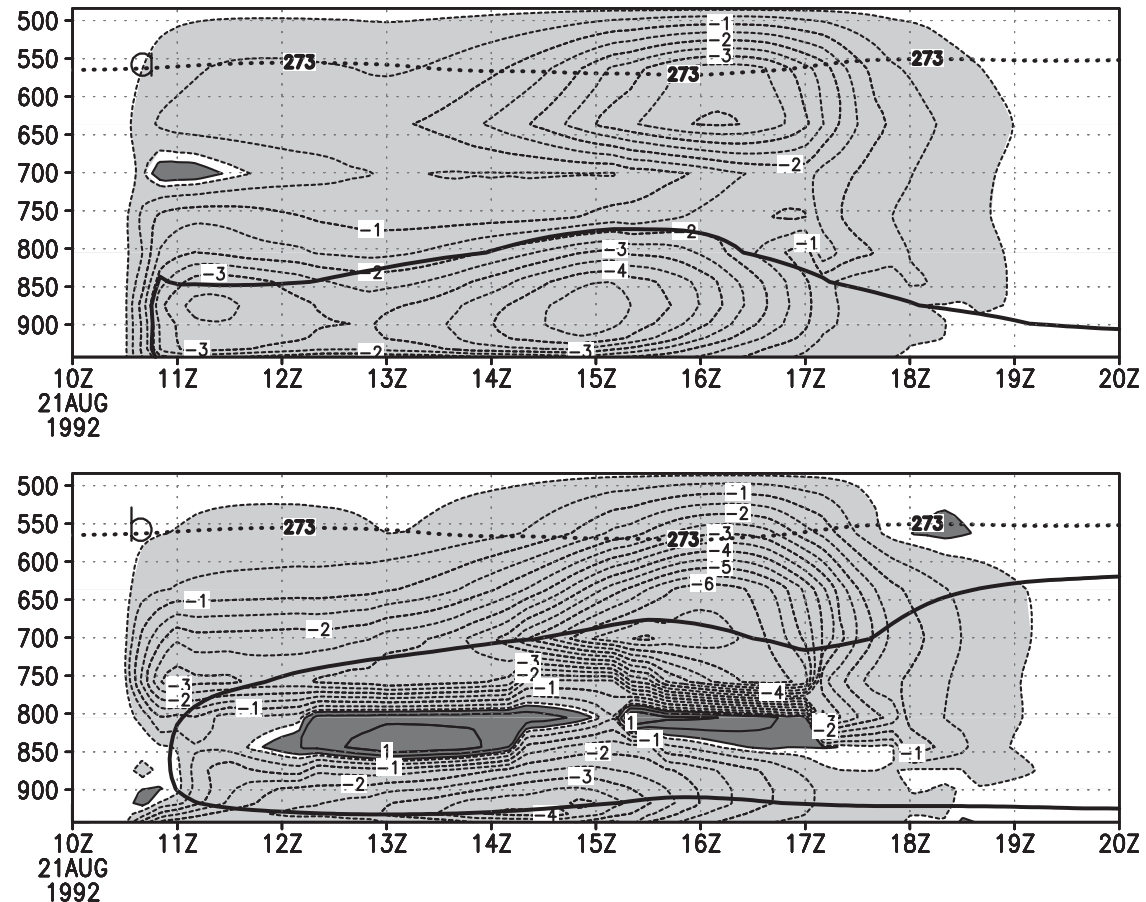

FIG. 7. HAPEX 92; 21 Aug squall line. (a) Differential heating $\left(\delta Q_{1}^{\mathrm{cv}} / C_{p}\right)$ and (b) drying $\left(\delta Q_{2}^{\mathrm{cv}} / C_{p}\right)$ by convection in SCM simulation. The $0^{\circ} \mathrm{C}$ isotherm is superimposed (black thick dotted line on both graphs). The wake and the dry tongue are outlined by the thick black lines in (a) and (b), respectively. Light gray and dark gray areas correspond to values below -0.1 and above $0.1 \mathrm{~K} \mathrm{~h}^{-1}$, respectively; contour spacing within these areas is $0.5 \mathrm{~K} \mathrm{~h}^{-1}$. 


\section{a. The $\delta \theta$ and $\delta q_{v}$ equations}

The driving sources of the wake temperature and humidity differences are the differential heating and drying due to deep convection $\left(\delta Q_{1}^{\mathrm{cv}}\right.$ and $\delta Q_{2}^{\mathrm{cv}}$ shown in Fig. 7, on which are superimposed the wake temperature and the dry tongue outlines, respectively). From the definition of the homogeneity level $p_{h}$, there is no differential heating (drying) above it (550 hPa here). As expected, there is a differential cooling within the wake, which vanishes at the wake top. In the free atmosphere, there is other differential cooling (negative $\delta Q_{1}^{\mathrm{cv}}$ ) due to rain evaporation and melting (see isoline $0^{\circ} \mathrm{C}$ ) within the precipitating downdraft and to convective heating in the $(x)$ region. For moisture (Fig. 7b), the dry tongue axis corresponds to differential drying (positive $\delta Q_{2}^{\mathrm{cv}}$ ) at the wake top, where the subsidence effect is stronger than the moistening by evaporation. In the lowest part of the wake, where the subsiding motion is weaker, the moistening effect dominates. Above the wake, there is differential moistening (negative $\delta Q_{2}^{\mathrm{cv}}$ ) due to rain evaporation within the precipitating downdraft and to convective drying in the $(x)$ region.

Figure 8 displays vertical profiles (up to $500 \mathrm{hPa}$ ) of the various terms of the $\delta \theta$ prognostic Eqs. (8). The double peak profile of the main cooling source $\left(\delta Q_{1}^{\mathrm{cv}}\right)$, previously analyzed in Fig. $7 \mathrm{a}$, is clearly visible, with maximum cooling in the wake and above $700 \mathrm{hPa}$. The term due to wake eddies, $\delta Q_{1}^{\mathrm{wk}}$ (spread, entrainment, and vertical velocity difference $\delta \omega$ displayed in Fig. 9), largely balances the $\delta Q_{1}^{\mathrm{cv}}$ term. Adjustment by gravity waves limits the wake intensification, especially at $1600 \mathrm{LT}$ during the mature stage. The large-scale contribution is weak. The same balance between convection and wake eddy sources exists for vapor (Fig. 10). However, it should be noted that the magnitudes are larger than for temperature, showing the importance of vapor processes and transport impacting the $Q_{2}$ apparent moisture sink. The last rows of Figs. 8 and 10 detail the contribution of the entrainment to wake eddy terms $\delta Q_{1}^{\mathrm{wk}}$ and $\delta Q_{2}^{\mathrm{wk}}$. By construction, it is active only above the wake. The entrainment is large for vapor whereas it is negligible for temperature. Because of the importance of vapor entrainment, the sensitivity of the SCM to $\delta \omega$ and to $e_{w}$ might be worth considering. However, such a study would require an analysis of the entrainment/detrainment processes that is beyond the scope of this paper. It will be left for further study.

\section{b. The $\bar{\theta}$ and $\overline{q_{v}}$ equations}

Figure 11 displays vertical profiles (up to $500 \mathrm{hPa}$ ) of the various terms of the $\bar{\theta}$ prognostic Eqs. (7). At $1600 \mathrm{LT}$ during the mature stage, above the wake top, the gridbox mean temperature evolution is driven by the convection
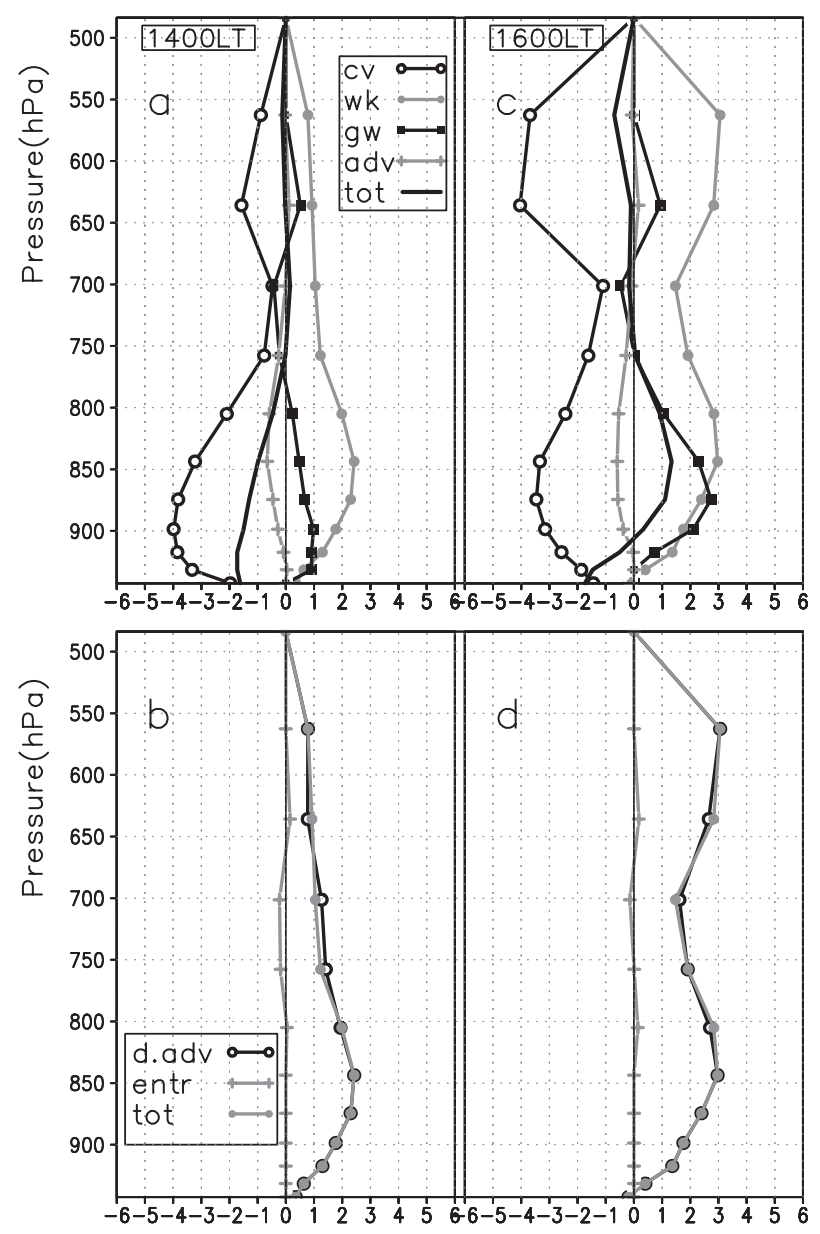

FIG. 8. HAPEX 92; 21 Aug squall line at (a),(b) 1400 and (c),(d) $1600 \mathrm{LT}$; all variables in $\mathrm{K} \mathrm{h}^{-1}$. (a), (c) Differential heating due to convection $\left(\delta Q_{1}^{\mathrm{cv}} / C_{p}\right)$ (black open circles) and to wakes $\left(\delta Q_{1}^{\mathrm{wk}} / C_{p}\right)$ (gray closed circles), damping by GW $\left[-\left(k_{\mathrm{gw}} / \tau_{\mathrm{gw}}\right) \delta \theta\right]$ (black closed squares), advection by $\bar{\omega}$ (gray crosses), and total heating tendency $\left(\partial_{t} \delta \theta\right)$ (continuous line). (b),(d) Decomposition of $\delta Q_{1}^{\mathrm{wk}} / c_{p}$ (black open circles $=$ differential advection, gray crosses $=$ entrainment, gray closed circles $=$ total).

scheme $Q_{1}^{\mathrm{cv}}$ because the wake contribution $Q_{1}^{\mathrm{wk}}$ is negligible. Within the wake, both terms are important with some opposite behavior. The apparent heat source $Q_{1}^{\mathrm{wk}}$ is positive above $900 \mathrm{hPa}$ and negative below, while the source $Q_{1}^{\mathrm{cv}}$ is negative around and above $900 \mathrm{hPa}$ and positive in a thin surface layer. The total effect is a cooling maximum at low levels and then a linear decrease up to the wake top. The decomposition of the wake contribution $Q_{1}^{\mathrm{wk}}$ (Fig. 11d) indicates that the differential vertical advection always warms $\bar{\theta}$, whereas the wake spreading causes strong cooling up to $850 \mathrm{hPa}$ and warming at the wake top. Similar behavior is found during the growth stage at 1400 LT but with a weak magnitude.

For the mean vapor $\overline{q_{v}}$ evolution, the results are very different (Fig. 12). First, the wake contribution is intense 


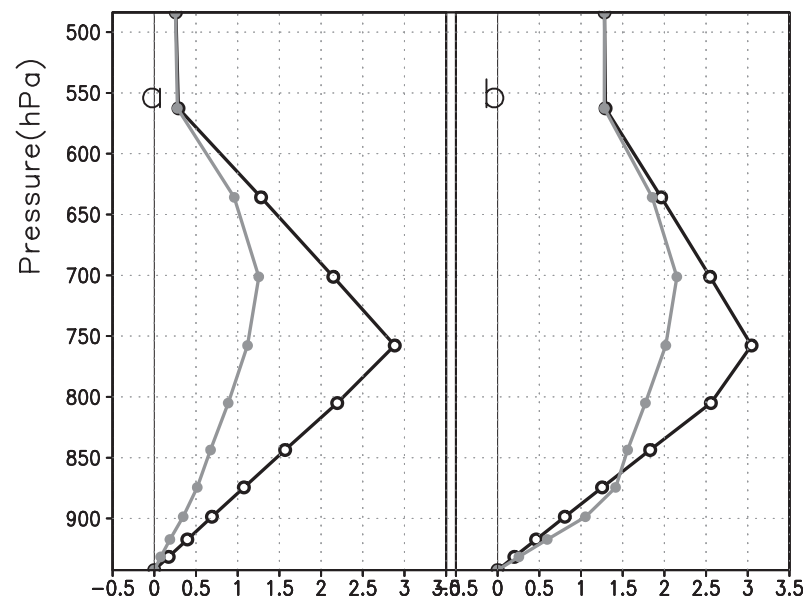

FIG. 9. HAPEX 92; 21 Aug squall line at (a) 1400 and (b) 1600 LT: vertical velocity difference $\delta \omega$ (black open circles) and the part due solely to the convective drafts $\delta \omega_{\mathrm{cv}}$ (gray closed circles).

both within and above the wakes up to $500 \mathrm{hPa}$ and the profile structure of the convection contribution $Q_{2}^{\mathrm{cv}}$ changes between the growth and mature stages, unlike the wake contribution $Q_{2}^{\mathrm{wk}}$. At $1400 \mathrm{LT}$, both contributions work together and equally by drying the grid box within the wake and moistening it above. At 1600 LT, the wake has the same effect with a much stronger magnitude, whereas the convection effect reverses with moistening below $850 \mathrm{hPa}$ and intense drying above. The decomposition of the wake contribution $Q_{2}^{\mathrm{wk}}$ (Fig. 12d) indicates that the wake spreading dominates and is opposite to the differential vertical advection. In short, we see that the wake processes reinforce the drying at the grid box scale over the whole wake depth mainly because of wake spread. In consequence, the wake coupling helps to lower the level of the maximum apparent moisture sink $Q_{2}$.

Figure 13 analyzes the transport of moist static energy as measured by $Q_{1}-Q_{R}-Q_{2}$ (Yanai et al. 1973) and the relative contribution of convection and wakes. Recall that this transport reflects moisture transport more than heat transport, which is weak. At 1400 LT (Fig. 13a), transports by convection and wakes work together and equally by drying the grid box within the wake and moistening it above. At 1600 LT (Fig. 13c), wakes transport vapor similarly and are more active, whereas the transport by convection is deeper and also more intense, removing vapor from below $600 \mathrm{hPa}$ to deposit it above. The total result of transport by convective and wake eddies is a deep layer of drying below $650 \mathrm{hPa}$ and moistening above. We see that the convection-wake coupled SCM simulation of this transport of moist static energy is in agreement with the CRM (Figs. 13b and 13d) except at 1400 LT below $800 \mathrm{hPa}$, where the total drying is underestimated.
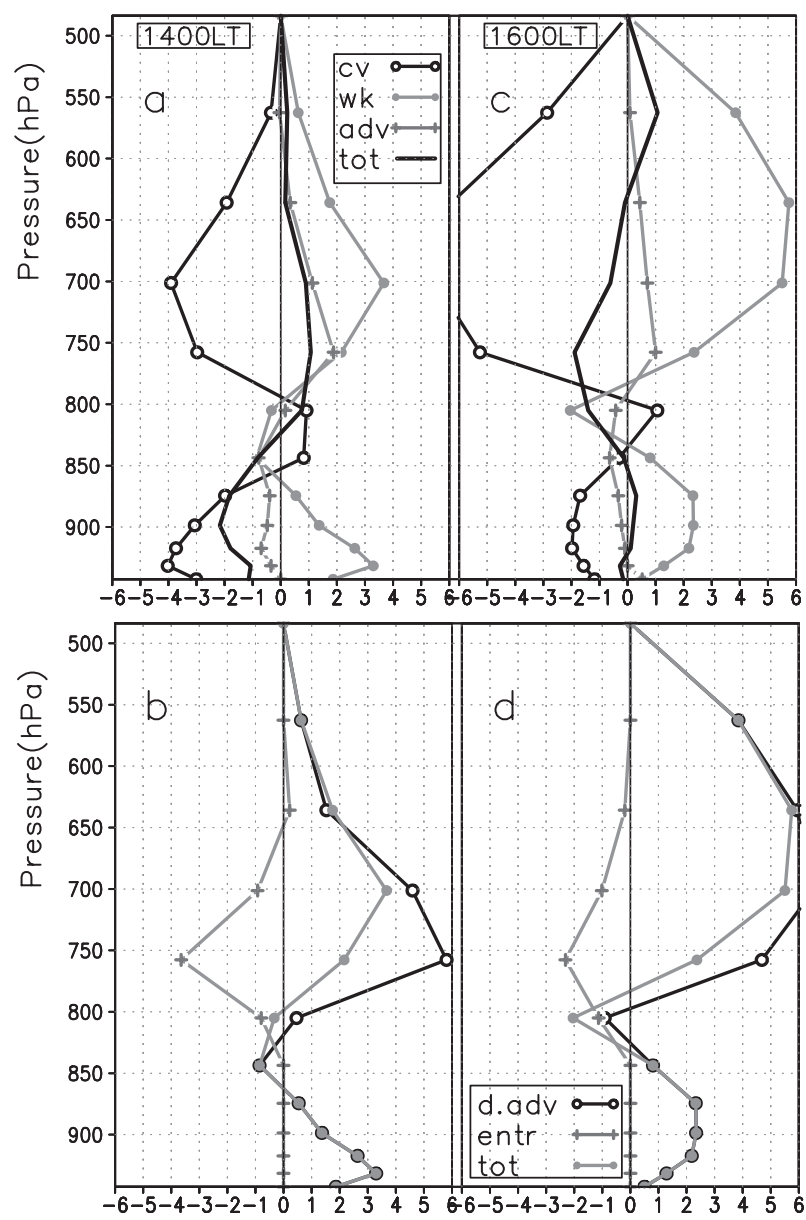

FIG. 10. As in Fig. 8, but for (a),(c) differential drying due to convection $\left(\delta Q_{2}^{\mathrm{cv}} / C_{p}\right)$ (black open circles) and to wakes $\left(\delta Q_{2}^{\mathrm{wk}} / C_{p}\right)$ (gray closed circles), advection by $\bar{\omega}$ (gray crosses), and total drying tendency $\left[-\left(L_{v} / C_{p}\right) \partial_{t} \delta q_{v}\right]$ (continuous line). (b),(d) Decomposition of $\delta Q_{2}^{\mathrm{wk}} / C_{p}$ (black open circles $=$ differential advection, gray crosses $=$ entrainment, gray closed circles $=$ total $)$

\section{c. Sensitivity analysis}

To study the sensitivity of the coupled wake-convection model to its six parameters $\left(k_{*}, \mathcal{E}_{\text {lift }}^{\mathrm{wk}}, k_{\mathrm{gw}}, D_{\mathrm{wk}}, w_{B}\right.$, and $\left.\sigma_{d, 0}\right)$, a series of simulations was performed in which each parameter was attributed values evenly distributed over a reasonable range.

It is worth noting that the first four parameters (the wake parameters) are interdependent as they appear as combinations in only three coefficients, once $k * \sqrt{2 \mathrm{WAPE}}$ has been substituted for $C_{*}$ : (i) the wake spreading coefficient reads $k * D_{\mathrm{wk}}^{1 / 2}$ in Eq. (4), (ii) the closure coefficient reads $k_{*}^{3} \mathcal{E}_{\text {lift }}^{\mathrm{wk}} D_{\text {wk }}^{1 / 2}$ or $k_{*}^{3} \mathcal{E}_{\text {lift }}^{\mathrm{wk}}$ in Eq. (9) when $D_{\text {wk }} S_{t}>1$ or $<1$ respectively, and (iii) the gravity wave damping coefficient reads $k_{\mathrm{gw}} D_{\mathrm{wk}}^{1 / 2}$ in Eqs. (8). Hence, the model is invariant under the transformations $(\lambda$ being an arbitrary number): $k_{*} \rightarrow \lambda k_{*}, \mathcal{E}_{\text {lift }}^{\mathrm{wk}} \rightarrow \lambda^{-2} \mathcal{E}_{\text {lift }}^{\mathrm{wk}}$ or 

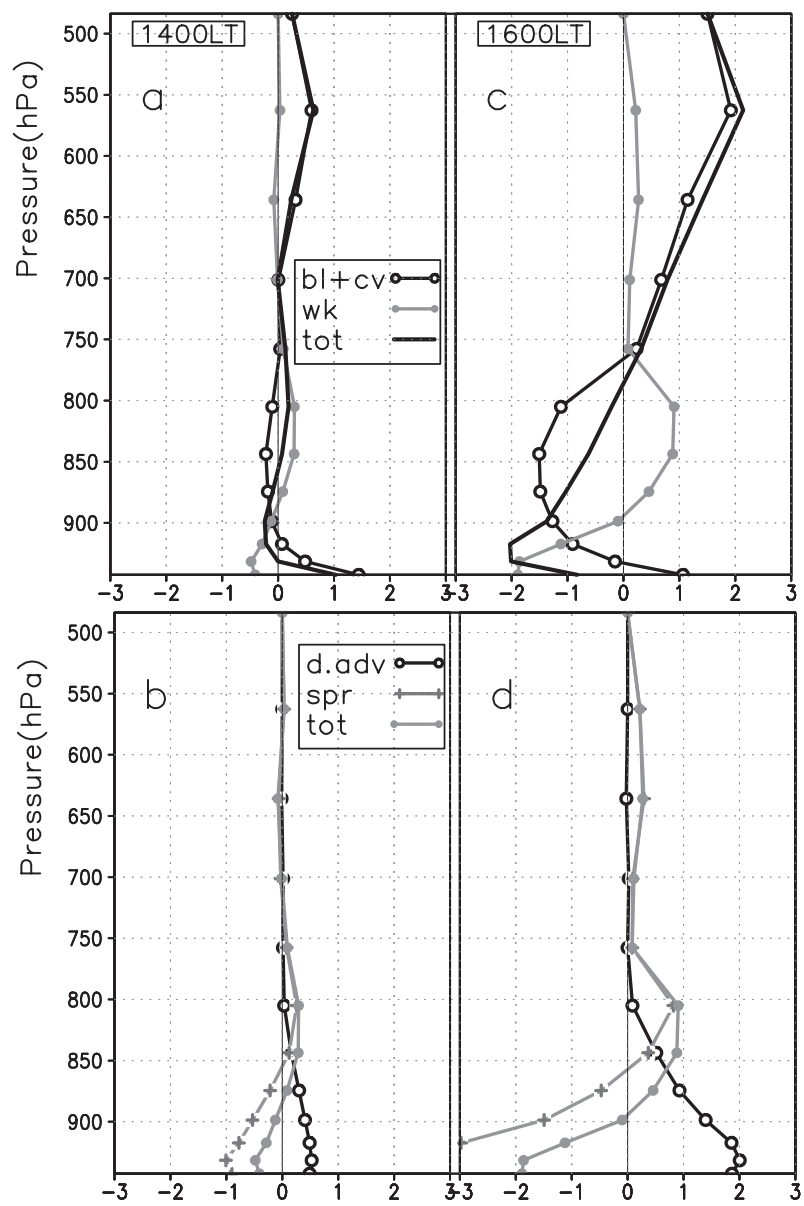

FIG. 11. As in Fig. 8, but for (a),(c) convective heating $\left[\left(Q_{1}^{\mathrm{bl}}+Q_{1}^{\mathrm{cv}}\right) / C_{p}\right]$ (black open circles), wake heating $\left(Q_{1}^{\mathrm{wk}} / C_{p}\right)$ (gray closed circles), and total heating $\left[\left(Q_{1}-Q_{\mathrm{R}}\right) / C_{p}\right]$ (continuous line). (b),(d) Decomposition of $Q_{1}^{\mathrm{wk}} / C_{p}$ (black open circles = differential advection, gray crosses $=$ spreading, gray closed circles $=$ total).

$\mathcal{E}_{\text {lift }}^{\mathrm{wk}} \rightarrow \lambda^{-3} \mathcal{E}_{\text {lift }}^{\mathrm{wk}}$ when $D_{\mathrm{wk}} S_{t}>1$ or $<1$, respectively, $k_{\mathrm{gw}} \rightarrow \lambda k_{\mathrm{gw}}$, and $D_{\mathrm{wk}} \rightarrow \lambda^{-2} D_{\mathrm{wk}}$. The last two ( $w_{B}$ and $\left.\sigma_{d, 0}\right)$ are independent and appear in the convective closure [Eq. (11)] and in the precipitating downdraft model respectively. Keeping in mind this interdependency of the first four parameters, we now study the sensitivity of the wake-convection coupled SCM to the six parameters, beginning with the most easily tractable cases.

\section{1) GRAVITy WAVE DAMPING EFFICIENCY $k_{\mathrm{gw}}$}

Gravity wave damping homogenizes temperature proportionally to the altitude $z$. Thus, an increase in the efficiency $k_{\mathrm{gw}}$ tends to weaken the wakes (i.e., lower their WAPE). The simulation results meet this expectation, since an increase in the damping efficiency entails slower and warmer wakes (Figs. 14c,d), yielding weaker deep convection (Fig. 14a). The wake humidity difference $\delta q_{v}$
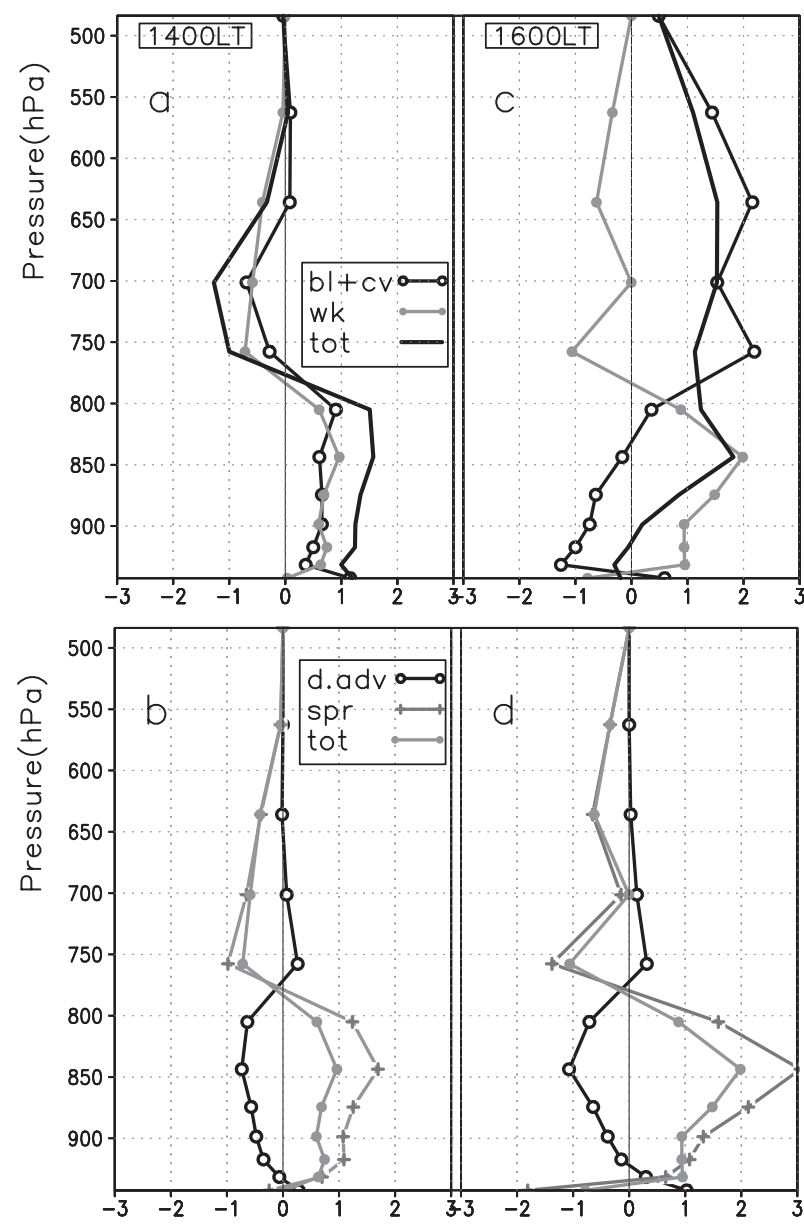

FIG. 12. As in Fig. 8, but for (a),(c) convective drying $\left[\left(Q_{2}^{\mathrm{bl}}+Q_{2}^{\mathrm{cv}}\right) / C_{p}\right]$ (black open circles), wake drying $\left(Q_{2}^{\mathrm{wk}} / C_{p}\right)$ (gray closed circles), and total drying $\left(Q_{2} / C_{p}\right)$ (continuous line). (b),(d) Decomposition of $Q_{2}^{\mathrm{wk}} / C_{p}$ (black open circles = differential advection, gray crosses $=$ spreading, gray closed circles $=$ total).

remains unchanged (Fig. 14e), which makes this sensitivity case especially simple. Moreover, the drying $Q_{2}$ stays invariable below the wake top (Fig. $14 \mathrm{~g}$ ), so that $\overline{q_{v}}, \overline{q_{v w}}$, and $\overline{q_{v x}}$ remain unchanged there. Hence the $\mathrm{CIN}_{x}$ is invariable (not shown), so convective intensity merely scales with ALP [Eq. (11)] and the time of precipitation maximum remains unchanged. The structure of the $Q_{1}$ profile and the $Q_{2}$ profile above wake top is not modified; just their magnitude increases with less gravity wave damping. Nevertheless, the sensitivity is weak because the $k_{\mathrm{gw}}$ coefficient has been multiplied by a factor of 5 .

\section{2) WAKE LIFTING EFFICIENCY}

Since the convective intensity is proportional to the lifting efficiency in Eq. (11), one expects an increase of the wake lifting efficiency $\mathcal{E}_{\text {lift }}^{\text {wk }}$ to yield more intense precipitation. This is what actually happens up to $1500 \mathrm{LT}$ 

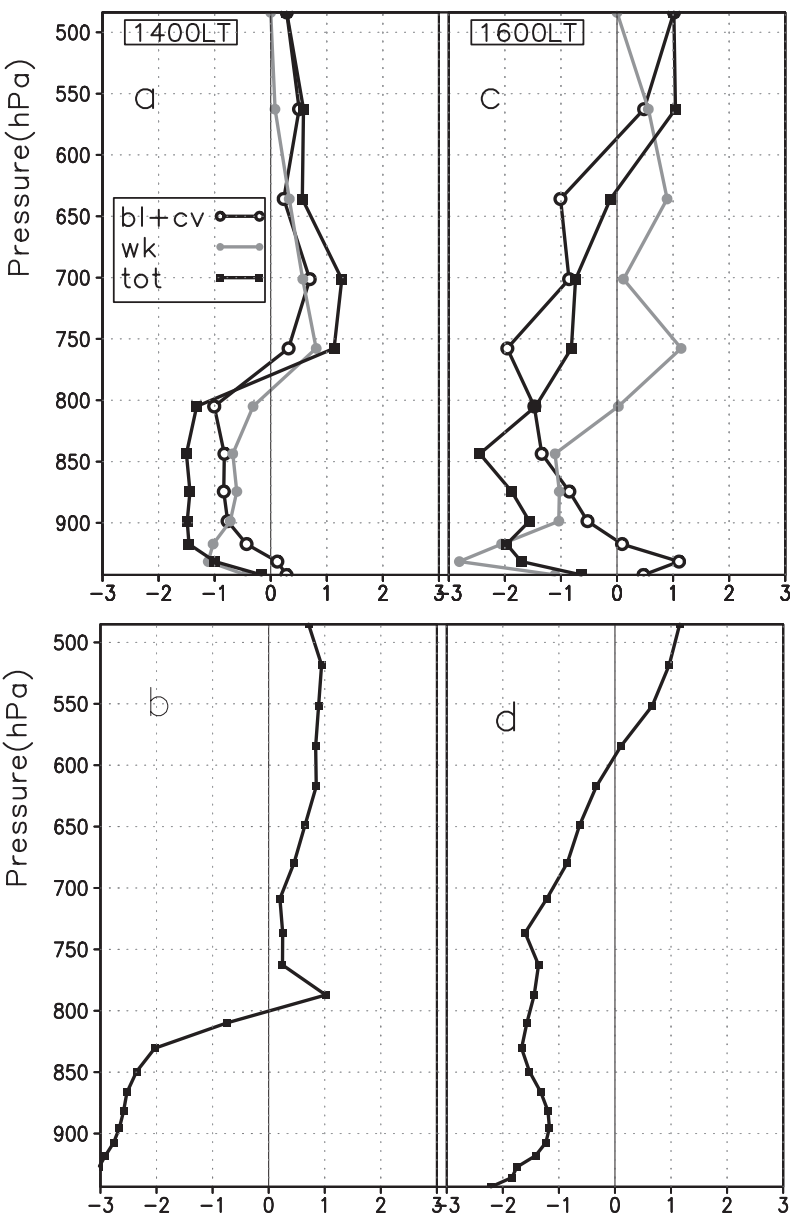

FIG. 13. As in Fig. 8, but for (a),(c) SCM simulation results; convective heating and drying difference $\left\{\left[\left(Q_{1}^{\mathrm{cv}}+Q_{1}^{\mathrm{bl}}\right)-\left(Q_{2}^{\mathrm{cv}}+\right.\right.\right.$ $\left.\left.\left.Q_{2}^{\mathrm{bl}}\right)\right] / C_{p}\right\}$ (black open circles), wake heating and drying difference $\left[\left(Q_{1}^{\mathrm{wk}}-Q_{2}^{\mathrm{wk}}\right) / C_{p}\right]$ (gray closed circles), and total difference $\left[\left(Q_{1}-\right.\right.$ $\left.\left.Q_{R}-Q_{2}\right) / C_{p}\right]$ (black closed squares). (b),(d) $\left[\left(Q_{1}-Q_{R}-Q_{2}\right) / C_{p}\right]$ in Méso-NH simulations.

(Fig. 15a). However, the changes induced in the lifting power and in the convective inhibition in turn modify the convective intensity, amplifying the increase before 1500 LT and yielding a decrease after 1600 LT. In accordance with this early increase of convective intensity, the wakes are cooler (Fig. 15d) and slightly deeper (Fig. 15b) and spread slightly faster (Fig. 15c). The wakes are moister over their whole depth (Fig. 15e); since $Q_{2}$ is again invariable below wake top, the increased $\delta q_{v}$ implies a decrease of humidity in the $(\mathrm{x})$ region, yielding a decrease of $\mathrm{CIN}_{x}$ (not shown; $\mathrm{CIN}_{x}$ at $1700 \mathrm{LT}$ is equal to $-7.5 \mathrm{~J} \mathrm{~kg}^{-1}$ and $-75 \mathrm{~J} \mathrm{~kg}^{-1}$ for $\mathcal{E}_{\text {lift }}^{\mathrm{wk}}=0.2$ and 0.4 , respectively), which explains the decrease in convective intensity mentioned earlier. Again, the shape of the $Q_{1}$ profile is invariable, the magnitude of the heating increasing with $\mathcal{E}_{\text {lift }}^{\mathrm{wk}}$. The $Q_{2}$ behavior is more complicated: the drying increases, as expected, below $600 \mathrm{hPa}$ but decreases between 600 and $400 \mathrm{hPa}$ (Fig. 15g). This occurs because for high values of $\mathcal{E}_{\text {lift }}^{\mathrm{wk}}$, the strongest convection occurs around $1500 \mathrm{LT}$, at a time when the $Q_{2}$ profile shows a minimum between 500 and $400 \mathrm{hPa}$. This minimum is particularly visible in Fig. 4d: $Q_{2}$ from the Méso-NH simulations is negative above $500 \mathrm{hPa}$ between 1400 and 1500 LT.

\section{3) WAKE SPREADING COEFFICIENT}

The first impact of a change in the wake spreading efficiency is a change in the convective intensity, since $k_{*}$ appears at the third power in the closure coefficient [Eq. (9)]. To analyze the effect of the wake spread per se, we modify $k_{*}$ and $\mathcal{E}_{\text {lift }}^{\mathrm{wk}}$ simultaneously so as to keep the closure coefficient (i.e., $\left.k_{*}^{3} \mathcal{E}_{\text {lift }}^{\mathrm{wk}}\right)$ constant $(\simeq 0.009$, the reference simulation value). The chosen range of $k_{*}$ values ( 0.25 to 0.65$)$ includes the range of values estimated from 3D and 2D CRM simulations $(1 / 3$ and $2 / 3$ respectively) or from observation of cold pools (0.5) by Bryan et al. (2005). As expected, increasing $k_{*}$ entails faster wake spreading (Fig. 16c) and shallower wakes (Fig. 16b). In consequence, the WAPE decreases (not shown) so the precipitation peak weakens. The vertical profile of temperature $\delta \theta$ (Fig. 16d) confirms the wake weakening when the spread increases (the temperature deficit drops from 11 to $3 \mathrm{~K}$ at the surface); the intermediate value $k_{*}=0.33$ of the REF simulation provides a temperature drop in agreement with observations $(8 \mathrm{~K})$. Again, the shape of the $Q_{1}$ profile is invariable (Fig. 16f) while its magnitude decreases. As far as water vapor is concerned (Fig. 16e), the situation is contrasted because of the large range of convective intensity spanned by this sensitivity case. The first two values of $k_{*}$ yield strong convection and a behavior similar to the $\mathcal{E}_{\text {lift }}^{\mathrm{wk}}$ sensitivity case: stronger convection is associated with moister wakes, invariable $Q_{2}$ below wake top (Fig. 16g), higher $\mathrm{CIN}_{x}$, and earlier precipitation maximum. In contrast, higher $k_{*}$ values yield weak convection, weak $Q_{2}$ above wake top, and a complete disappearance of the dry tongue for the highest $k_{*}$ values. Also, for these very high spreading rates, $Q_{2}$ increases with $k_{*}$ at very low levels because of the simultaneous drying and growth of the wakes.

\section{4) WAKE DENSITY $D_{\mathrm{wk}}$}

Since $D_{\mathrm{wk}}$ appears in the three coupling coefficients (wake spreading, convective closure, and gravity wave damping coefficients), an increase of $D_{\mathrm{wk}}$ will result in a combination of the previous effects (i.e., an increase in spreading and in damping by gravity waves, which both tend to yield warmer and shallower wakes together with weaker convection, but with opposite effects on spreading rates). The closure coefficient is not 

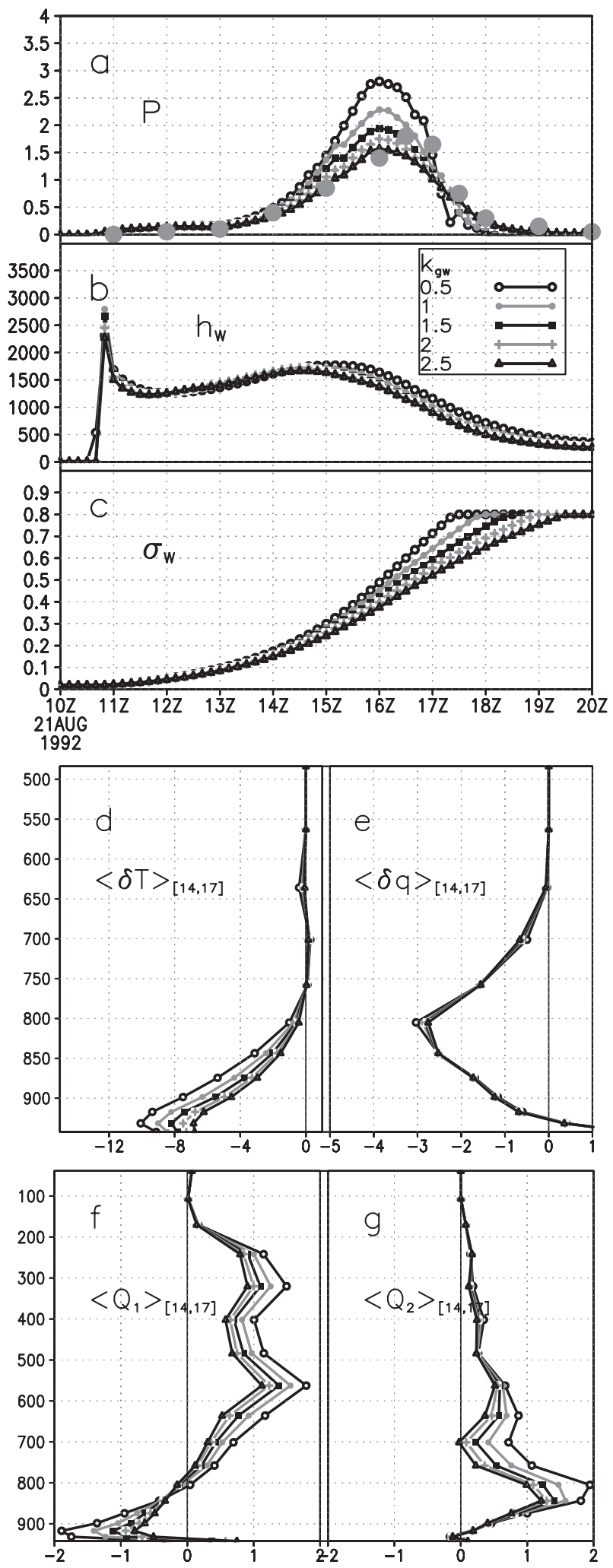

FIG. 14. HAPEX 92; 21 Aug squall line. Time series of (a) precipitation, (b) wake height, and (c) $\sigma_{w}$. Vertical profiles of average values between 1400 and $1700 \mathrm{LT}$ of (d) $\delta \theta$, (e) $\delta q_{v}$, (f) $Q_{1} / C_{p}$, and (g) $Q_{2} / C_{p}$ simulated by the SCM for various values of the tunable affected, since $D_{\mathrm{wk}} S_{t}<1$. Simulations do show that an increase of $D_{\mathrm{wk}}$ entails warmer and shallower wakes (Figs. $17 \mathrm{~b}$ and $17 \mathrm{~d}$, respectively), together with weaker convection (Fig. 17a). The spreading rate increases with $D_{\text {wk }}$ (Fig. $17 \mathrm{c}$ ), although $C_{*}$ decreases, because wakes become more numerous. These results are very similar to those obtained when varying the spreading efficiency. Especially, stronger convection is again associated with moister wakes (Fig. 17e), invariable $Q_{2}$ below wake top (Fig. $17 \mathrm{~g}$ ), and increased $Q_{2}$ in the 700-hPa region.

\section{5) Convective updraft Velocity: $w_{B}$}

The parameter $w_{B}$ appears in the convective closure relation [Eq. (11)]. It plays a role opposite to that of $\mathcal{E}_{\text {lift }}^{\mathrm{wk}}$ (increasing the convective updraft velocity is expected to yield less intense precipitation) and modulates the sensitivity of convection to the $\mathrm{CIN}_{x}$ : the higher $w_{B}$ is, the lower the sensitivity to $\mathrm{CIN}_{x}$. Simulation results confirm these effects. Lowering $w_{B}$ yields modifications of the various variables very similar to those obtained when increasing $\mathcal{E}_{\text {lift }}^{\mathrm{wk}}$. In particular, lower values of $w_{B}$ correspond to earlier maxima of precipitation (Fig. 18a) and moister wakes (Fig. 18e), which entail, as shown for the $\mathcal{E}_{\text {lift }}^{\mathrm{wk}}$ sensitivity case, higher $\mathrm{CIN}_{x}$. However, because of the higher sensitivity to $\mathrm{CIN}_{x}$, the decrease in precipitation is faster than it is in the $\mathcal{E}_{\text {lift }}^{\mathrm{wk}}$ sensitivity case. In consequence, the precipitation peak becomes narrower when it comes earlier, giving the precipitation plot Fig. 18a its very characteristic appearance. Because of the narrowness of the early peaks, the strong decrease of $Q_{2}$ between 600 and $400 \mathrm{hPa}$ is more apparent than in the $\mathcal{E}_{\text {lift }}^{\mathrm{wk}}$ sensitivity case.

\section{6) Precipitating Downdraft CROss SECTION: $\sigma_{d 0}$}

The parameter $\sigma_{d 0}$ controls the evaporation rate of precipitation: a larger $\sigma_{d 0}$ is expected to yield larger evaporation and hence a smaller moisture sink and heat source, together with an enhancement of wakes thanks to the larger low-level cooling generated by evaporation. The simulation results show that these various mechanisms do occur but that they interact in a nontrivial way. In response to an increase in $\sigma_{d 0}$, the wakes become cooler and moister (Figs. 19d,e). The associated increase of ALP induces more intense convection (not shown) ranging from 0.065 to $0.11 \mathrm{~kg} \mathrm{~m}^{-2} \mathrm{~s}^{-1}$ when $\sigma_{d 0}$

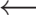

coefficient $k_{\mathrm{gw}}: k_{\mathrm{gw}}=0.5,1,1.5,2,2.5$ (curves with black open circles, gray closed circles, black closed squares, gray crosses, and black triangles, respectively). 

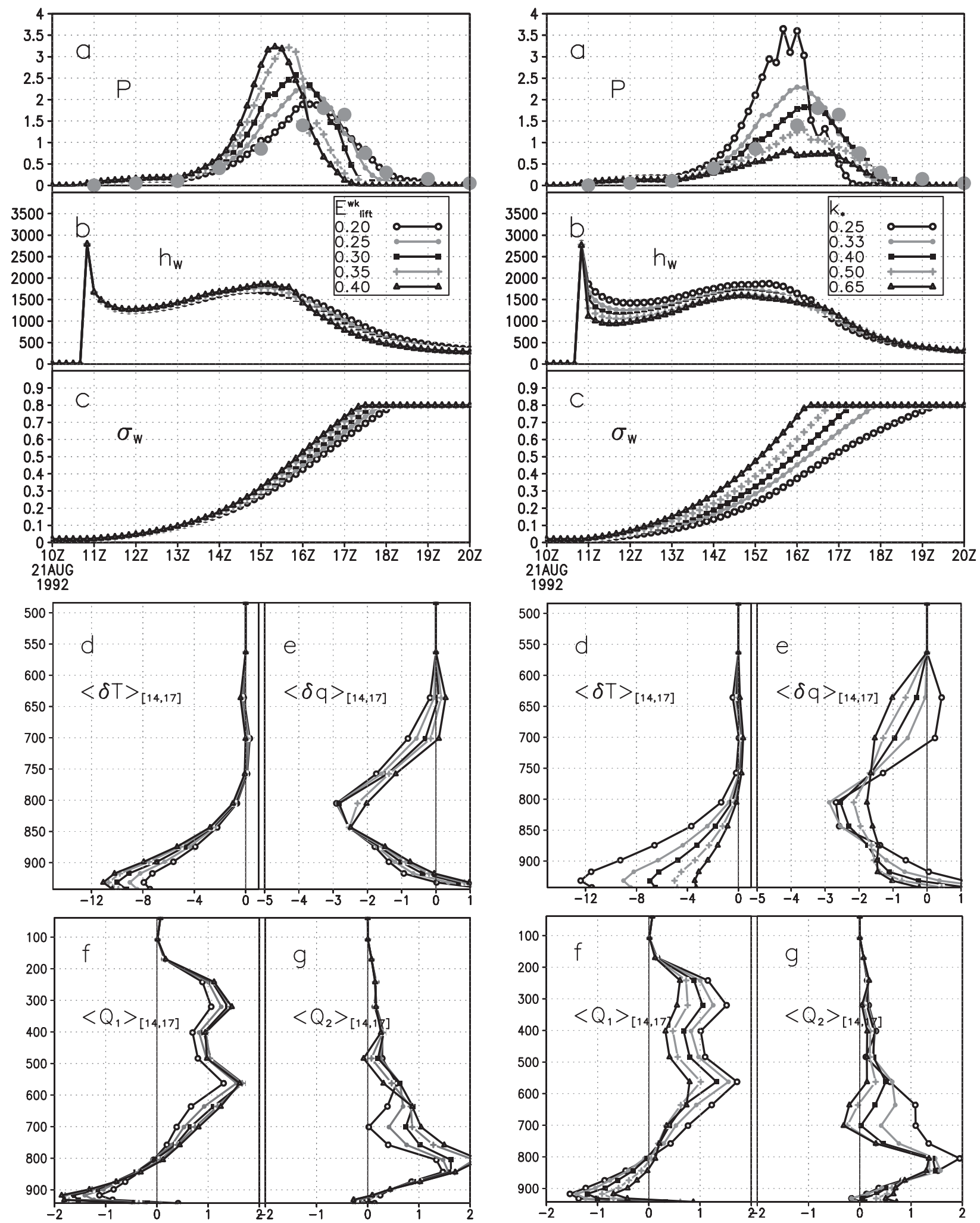

FIG. 15. As in Fig. 14, but for various values of the tunable coefficient $\mathcal{E}_{\text {lift }}^{\text {wk }}: \mathcal{E}_{\text {lift }}^{\text {wk }}=0.20,0.25,0.30,0.35,0.40$ (curves with black open circles, gray closed circles, black closed squares, gray crosses and black triangles, respectively).

FIG. 16. As in Fig. 14, but for various values of the tunable coefficient $k_{*}: k_{*}=0.25,0.33,0.40,0.50,0.65$ (curves with black open circles, gray closed circles, black closed squares, gray crosses, and black triangles, respectively); $\mathcal{E}_{\text {lift }}^{\mathrm{wk}} k_{*}^{3}=0.009$ is uniform among these simulations: $\mathcal{E}_{\text {lift }}^{\mathrm{wk}}=0.576,0.250,0.141,0.072,0.033$, respectively. 

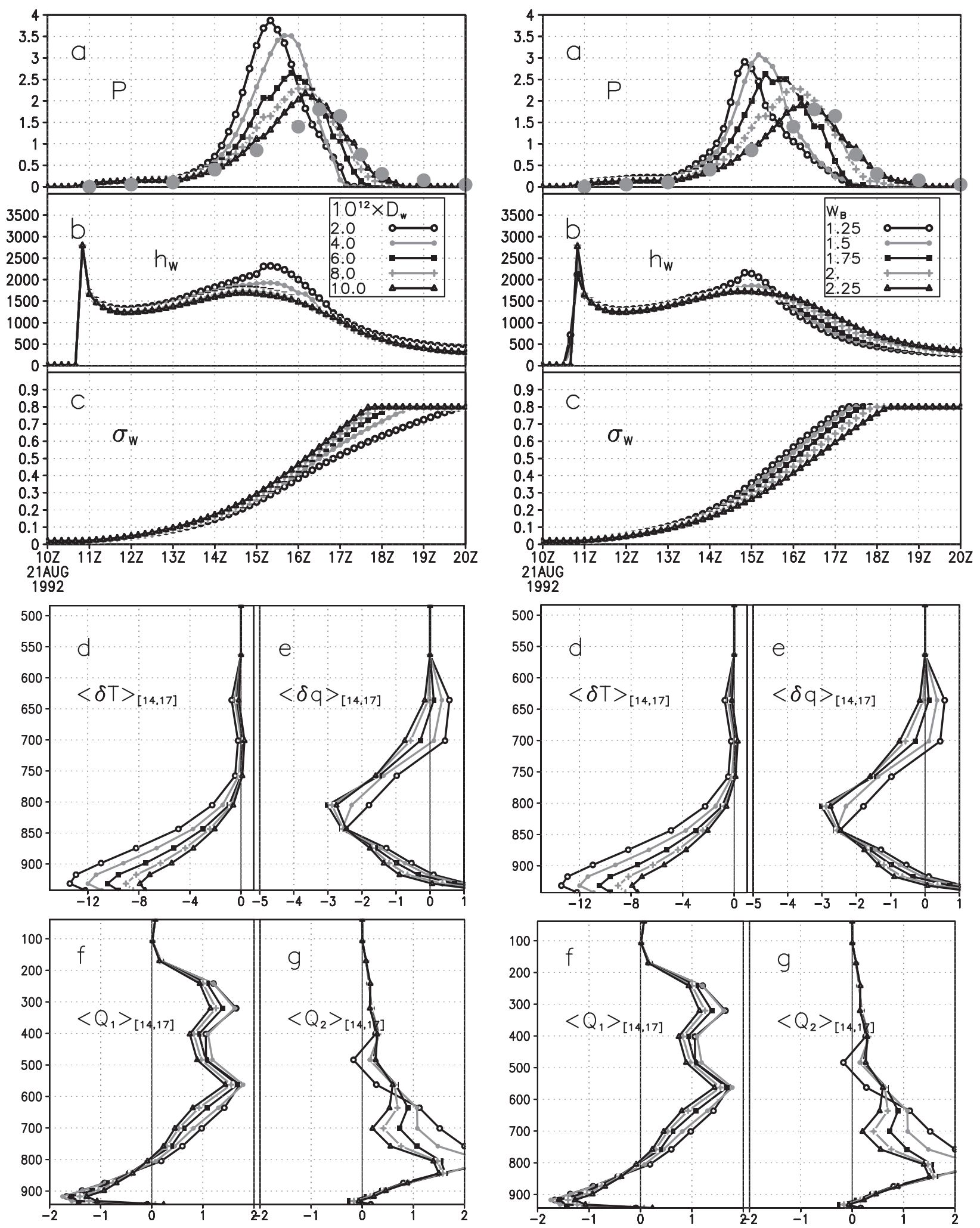

FIG. 17. As in Fig. 14, but for various values of the final wake density $D_{w 1}: D_{w 1}=2 \times 10^{-12}, 4 \times 10^{-12}, 6 \times 10^{-12}, 8 \times 10^{-12}, 10 \times$ $10^{-12} \mathrm{~m}^{-2}$ (curves with black open circles, gray closed circles, black closed squares, gray crosses, and black triangles respectively).

FIG. 18. As in Fig. 14, but for various values of the convective updraft velocity $w_{B}: w_{B}=1.25,1.5,1.75,2,2.25 \mathrm{~m} \mathrm{~s}^{-1}$ (curves with black open circles, gray closed circles, black closed squares, gray crosses, and black triangles, respectively). 
varies from 0.005 to 0.04 . However, a larger amount of precipitation evaporates, so the surface precipitation stays nearly constant (Fig. 19a). This compensation is also visible in the $Q_{1}$ profile (Fig. 19f), which appears nearly invariable above $800 \mathrm{hPa}$, the increase in evaporative cooling being canceled by the increase in convection intensity. Below $800 \mathrm{hPa}$, on the other hand, $Q_{1}$ is negative and the two processes contribute to an increase in the low-level cooling. The same is true for the $Q_{2}$ profile, except for the highest value of $\sigma_{d 0}$, which appears to correspond to a completely different regime.

\section{Maritime convection: The TOGA case}

\section{a. Case description and experimental design}

To check that the coupled wake and deep convection scheme was also appropriate to treat a case of less intense wake, we selected a maritime squall line observed during TOGA COARE and used by Bechtold et al. (2000) for an international SCM intercomparison project organized by Working Group 4 ("Precipitating Convective Cloud Systems") of GCSS. This well-documented case study of a mature SL (Jorgensen et al. 1997; Montmerle and Lemaitre 1998) was simulated by 2D and 3D CRMs (Redelsperger et al. 2000), allowing the evaluation of eight SCMs. In comparison with the HAPEX-Sahel SL, the wake associated with this SL was thinner and weaker (0.9-km depth, 3-4-K temperature drop).

The experiment design followed exactly what was done in Bechtold et al. (2000). The CRM simulations provided budgets for a $150 \times 100 \mathrm{~km}^{2}$ domain moving with the SL from which forcings were computed for the SCMs. However, this case is quite different from the HAPEX one in two respects. First, the initiation of the system is possible only if some artificial perturbation is introduced at the beginning (a cool bubble for the CRMs; some arbitrary ALE and ALP for the coupled wake-convection model). Second, because of the small size of the domain, CRMs have to use open lateral boundary conditions, which implies that SCM forcings reflect not only the large-scale forcings but also the effect of the SL itself. Hence, simulations performed with the coupled wake-convection scheme in this framework do not allow an analysis of the scheme response to largescale forcings, but rather make it possible to analyze the way the wake model operates.

The KE scheme did participate in this international SCM intercomparison as part of the LMDZ GCM. Its present coupling with the wake model was performed with the following configuration:

- Because Bechtold et al. (2000) did not provide the forcing term by the PBL that we have for the HAPEX-Sahel
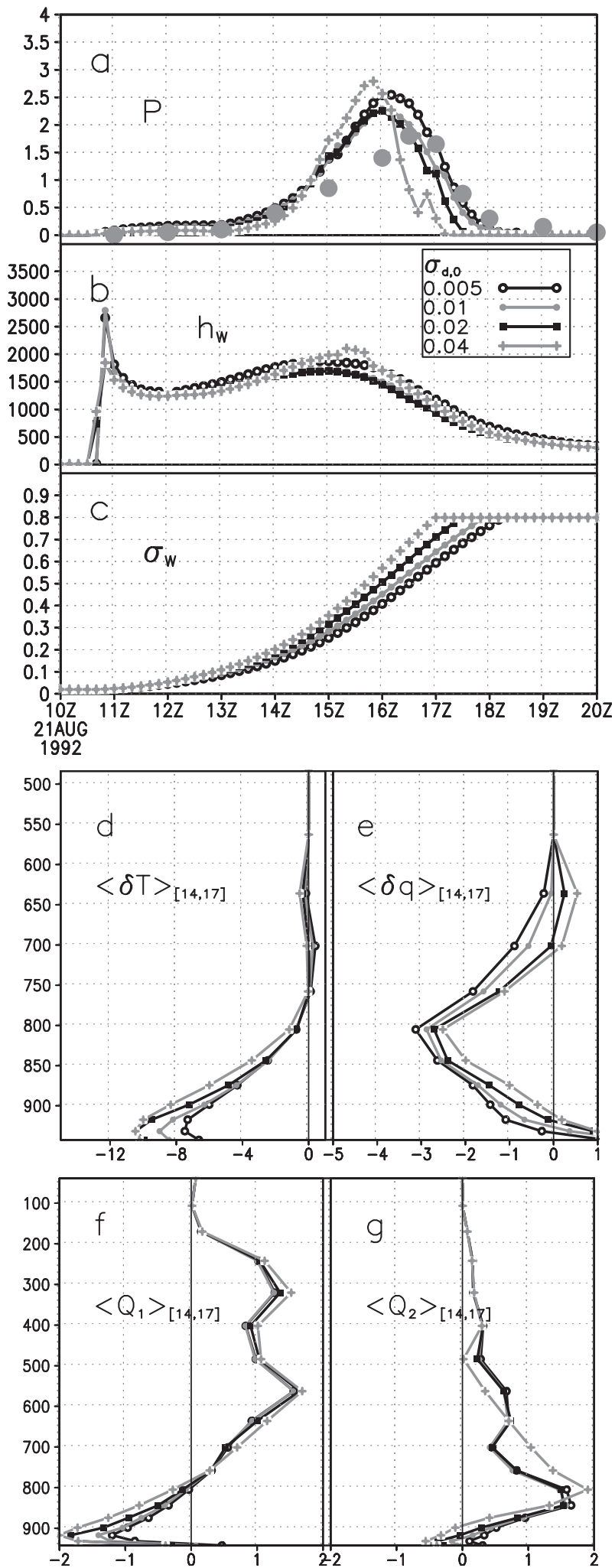

FIG. 19. As in Fig. 14, but for various values of the precipitating downdrafts cross section $\sigma_{d, 0}: \sigma_{d, 0}=0.005,0.01,0.02,0.04$ (curves with black open circles, gray closed circles, black closed squares, and gray crosses, respectively). 
$\mathrm{SL}$, in this section the wake and convection schemes will be used in conjunction with the standard LMDZ4 boundary layer scheme (Hourdin et al. 2006). The PBL scheme is not modified for the coupling with the convection scheme: its role is merely to act upon the temperature and humidity profiles. Therefore, the sole sources of ALE and ALP are the forced source and the wake scheme.

- Initiation of convection is obtained by providing forced ALE $\left(10 \mathrm{~J} \mathrm{~kg}^{-1}\right.$ for the first hour, then $1 \mathrm{~J}$ $\left.\mathrm{kg}^{-1}\right)$ and ALP $\left(0.1 \mathrm{~W} \mathrm{~m}^{-2}\right.$ for the first hour, then $0.01 \mathrm{~W} \mathrm{~m}^{-2}$ ).

\section{b. The simulation}

The parameter values used in this case are listed in Table 1. Compared to the HAPEX case, some parameter changes were necessary in order to simulate the TOGA case properly with the coupled wake-convection scheme. First, to represent a mature SL with a single density current, a low constant wake density, $D_{\mathrm{wk}}=4 \times$ $10^{-12} \mathrm{~m}^{-2}$, was imposed and the initial wake fractional area was increased to $\sigma_{w}=0.1$. Second, since the domain moves with the system, a confined configuration was assumed: $\eta=0$ in Eqs. (5) and (6). Note that the $(1-\eta)$ terms, which represent the effect of boundary conditions on the wakes, are proportional to $\bar{\omega}$. These terms are especially important since the small size of the domain implies large values for $\bar{\omega}$. Finally, it turned out that it was necessary to use a higher value for the spread efficiency, $k_{*}=0.53$ (smaller values lead to weak convection). The high value of $k_{*}$ might be due to the structure of the squall line being more $2 \mathrm{D}$ than in the HAPEX case. Nevertheless, these parameter values are physically sound and in agreement with CRM estimates of $k_{*}$.

\section{1) WAKE BEHAVIOR}

Thanks to the ALE and ALP forcings, convective precipitation started immediately at the beginning of the simulation (Fig. 21a). The wake appeared after $40 \mathrm{~min}$, as is visible from the WAPE curve (Fig. 20a) and the wake depth curve (Fig. 20b). After a transient phase lasting $1 \mathrm{~h}$, the wake depth stabilized around $700 \mathrm{~m}$, while the maximum temperature deficit increased steadily from 0 to $4 \mathrm{~K}$ (Fig. 20c), in reasonable agreement with Montmerle et al. (2000), who give $900 \mathrm{~m}$ and $3 \mathrm{~K}$ for the depth and the temperature deficit, respectively.

Similarly to the HAPEX case, the vapor field exhibited a dry tongue $\left(-5 \mathrm{~g} \mathrm{~kg}^{-1}\right)$ centered around the wake top (Fig. 20d). However, the moisture difference $\delta q_{v}$ was clearly more negative than in the HAPEX case; in particular, there was no moist layer close to the surface.
The spread velocity reached $3.5 \mathrm{~m} \mathrm{~s}^{-1}$ sharply at wake onset and then gradually increased to $6 \mathrm{~m} \mathrm{~s}^{-1}$ at $5 \mathrm{~h}$ where it stayed until the end (Fig. 20a). The wake area $\sigma_{w}$ again showed a quasi-exponential growth up to $50 \%$.

\section{2) WAKE FEEDBACK ON CONVECTION TRIGGERING AND INTENSITY}

Similarly to the HAPEX case, the lifting energy due to the wake rapidly exceeded the $\left|\mathrm{CIN}_{x}\right|$, enabling convection when the ALE forcing was stopped (Fig. 21d). After some oscillations, the WAPE increased gradually from 20 to $60 \mathrm{~J} \mathrm{~kg}^{-1}$ and the lifting power from $0.1 \mathrm{up}$ to $0.3 \mathrm{~W} \mathrm{~m}^{-2}$. Since the $\left|\mathrm{CIN}_{x}\right|$ stayed between 1 and $2.5 \mathrm{~J} \mathrm{~kg}^{-1}$ throughout the simulation, the denominator of the closure relation Eq. (11) varied by $20 \%$ at most, so convective intensity was mostly driven by $\mathrm{ALP}_{\mathrm{wk}}$ : convective precipitation increased from 1 to $3 \mathrm{~mm} \mathrm{~h}^{-1}$ when $\mathrm{ALP}_{\mathrm{wk}}$ increased from 0.1 to $0.3 \mathrm{~W} \mathrm{~m}^{-2}$.

In short, this TOGA case simulation demonstrates the ability of the wake model to simulate shallow maritime wakes as well as deep continental ones.

\section{Conclusions}

The wake parameterization coupled with the Emanuel's convection scheme described in the first part of this series of papers has been intensively tested in a SCM framework. The main goals were to verify that the behavior of this new parameterization was physically correct and that it did improve the KE convection scheme, and to provide guidelines for tuning the parameters for its further implementation in a 3D GCM.

For this purpose, we used two opposite cases of convection, over continent and ocean, well documented by observations and by CRM simulations to provide initialization, forcing data, and verification diagnoses. They corresponded to a case of initial development of a continental squall line observed during the HAPEX 1992 campaign and to a maritime case of a squall line observed during TOGA COARE. The first result was that the wake model correctly simulated the contrasting characteristics (intensity, depth, and structure) of these two wake cases, in agreement with observations-that is, a deep/intense wake $(1.8 \mathrm{~km},-8 \mathrm{~K})$ and a shallower/weaker one $(0.7 \mathrm{~km}$, $-4 \mathrm{~K}$ ) for the HAPEX and TOGA COARE cases, respectively. This result was quite robust and only slightly sensitive to the choice of parameters of the wake model.

As the CRM simulations of the TOGA COARE case were performed on a domain of relatively small size $\left(100 \times 150 \mathrm{~km}^{2}\right)$ and in a framework moving at the squall line propagation speed $(\eta=0)$, this case was far from what happens in a GCM, so it could not be used to test the parameterization in detail. So only the HAPEX case 

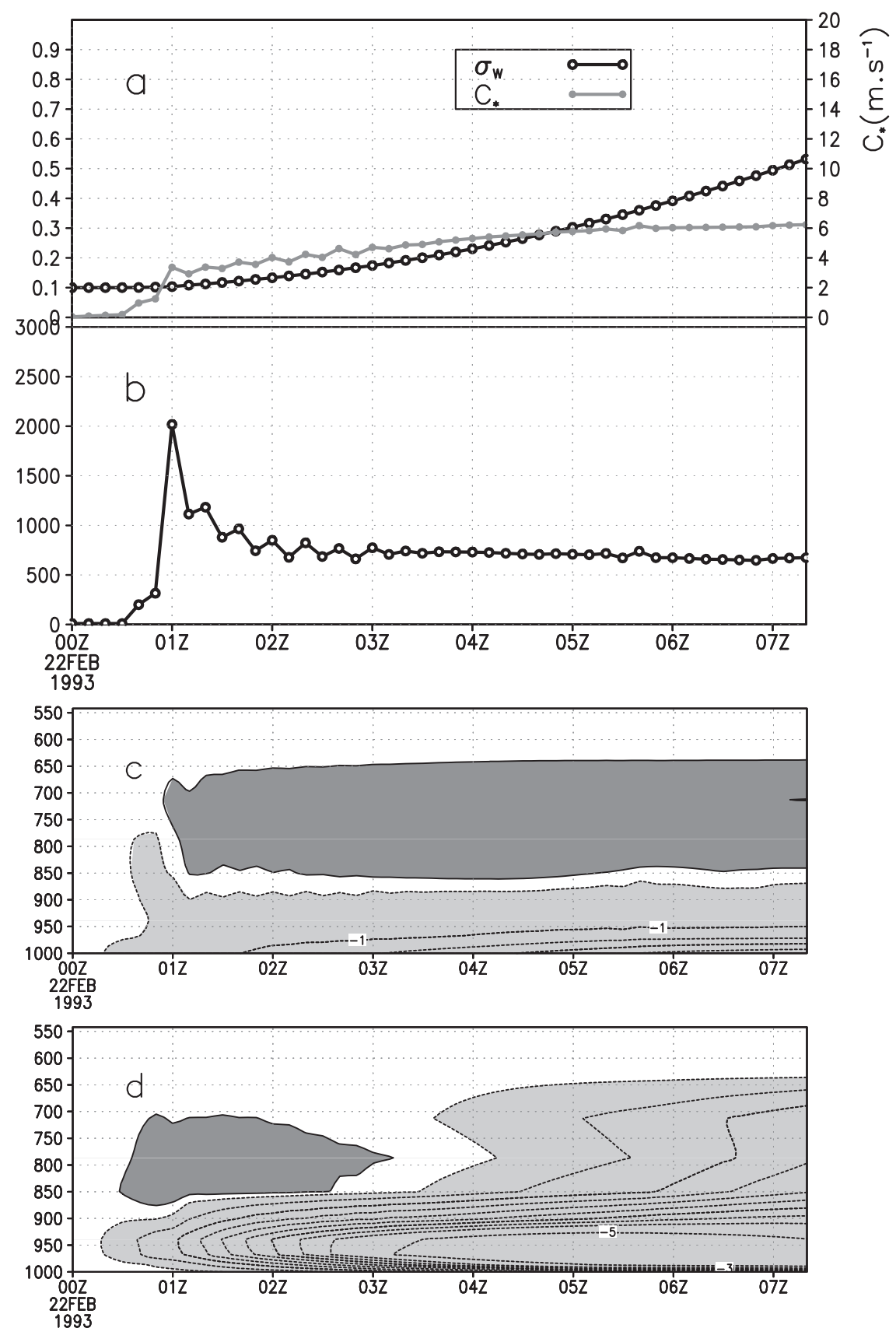

FIG. 20. As in Fig. 3, but for the TOGA COARE 22 Feb 1993 squall line.

performed in an Eulerian framework and on a large domain $\left(300 \times 300 \mathrm{~km}^{2}\right)$ was intensively used to explore the sensitivity to the parameterization parameters. To analyze the working of the coupled model specifically, all other parameterizations were removed; in particular, the effect of boundary layer processes was represented by a forcing provided by a CRM simulation of that case. The six parameters of the model were tuned in order to obtain precipitation time series and $Q_{1}$ and $Q_{2}$ profiles in acceptable agreement with the CRM simulation results (no fine tuning was attempted since it is expected that the tuning will eventually depend on the other parameterizations, especially the PBL one). With this rough tuning, the model appears to be successful in several respects. First, it does simulate a self-sustaining convective system with deep convection yielding precipitation, $Q_{1}$, and $Q_{2}$ profiles similar to those simulated by the CRM. Second, the water vapor field and the related 

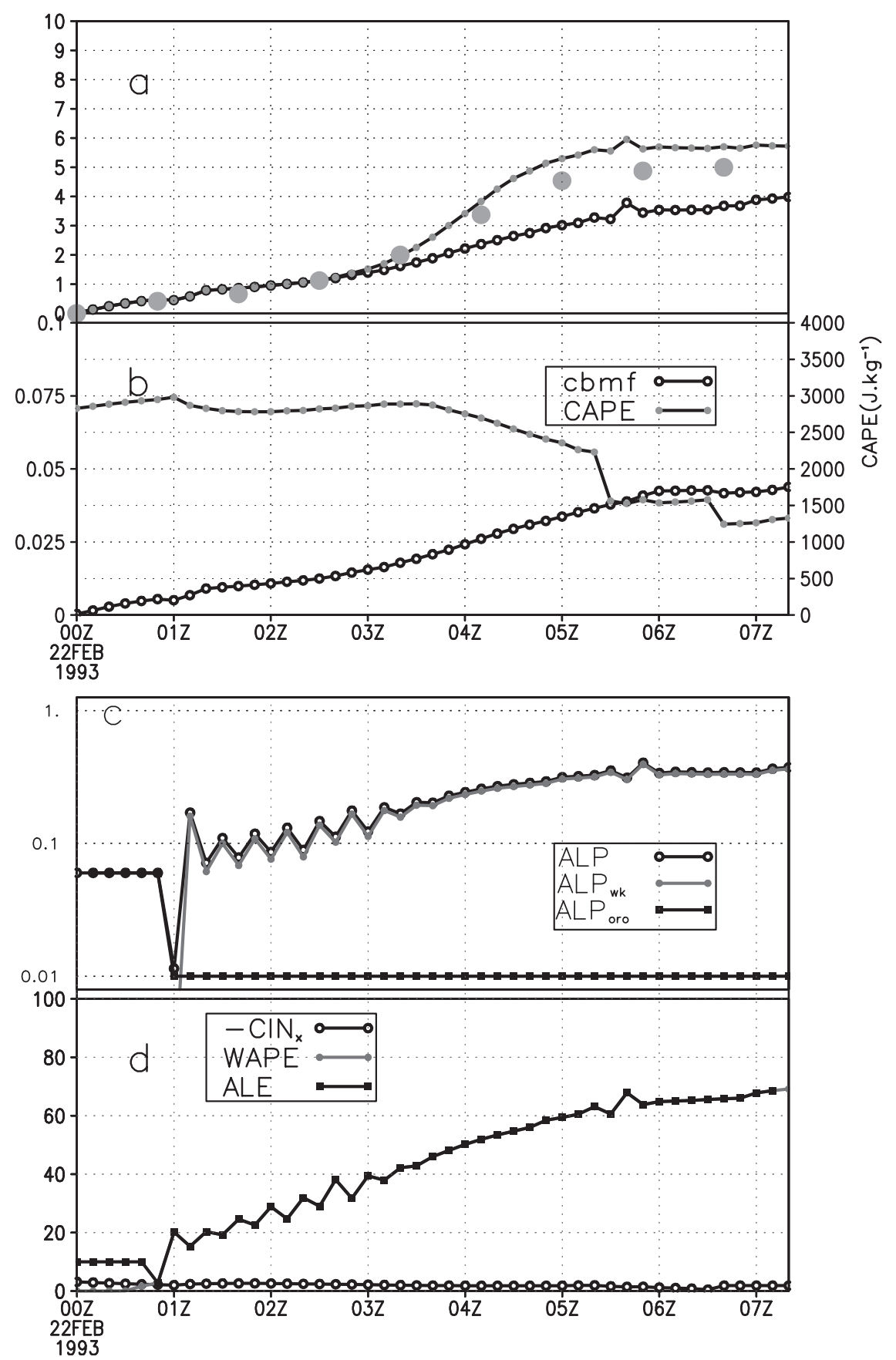

FIG. 21. As in Fig. 2, but for the TOGA COARE 22 Feb 1993 squall line.

variables, such as the moisture sink $Q_{2}$, display features in accordance with expectations and the CRM simulation: the SCM reproduces the thin moistening layer close to the surface; the wakes display a thin moist surface layer and a dry tongue above; and the moisture transport (as described by the field $Q_{1}-Q_{2}$ ) simulated by the SCM agrees with the CRM one both during the initial stage (except for an underestimation at low levels) and in the mature stage. Simulating a reasonable $Q_{2}$ field is one of the great challenges of convective parameterizations. The coupled wake-convection scheme appears to make some achievements in that respect.

Tests on the HAPEX case also show that the standard Emanuel convection scheme is drastically improved, both for the convection evolution and its impact, by the introduction of the wake model and of the ALE and 
ALP to treat the triggering and closure of the convection scheme. Only the coupling with the wake model allows the atmosphere stabilization and drying at low levels.

Sensitivity studies relative to each of the six parameters have been presented; they should help to reach a definite tuning when the coupled scheme is implemented in a fully fledged GCM. We have thus acquired better knowledge of the model's working and of the physical impact and meaning of each parameter. With the support of Table 1, our main findings and recommendations are as follows:

- The gravity wave damping $k_{\mathrm{gw}}$ will be a tuning parameter in the GCM, but it does not change the structure of the convection impact.

- The wake lifting efficiency $\mathcal{E}_{\text {lift }}^{\mathrm{wk}}$ controls the drying in the 800-600-hPa layer and the convection intensity. In the future, its dependency on the low-level shear will be introduced.

- 3D CRM simulations suggest a spreading coefficient $k_{*}$ of around $1 / 3$, which seems suitable.

- The wake density $D_{\mathrm{wk}}$ is a crucial parameter, which can be estimated from satellite IR imagery and presents a strong diurnal variation. It is proposed that its evolution be modeled in the future.

- The convective updraft velocity $w_{B}$ must be taken in the 1-2 $\mathrm{m} \mathrm{s}^{-1}$ range, whereas the precipitating downdraft cross section $\sigma_{d 0}$ can be taken as in the KE scheme.

The HAPEX continental deep convection case appeared very useful to test intensively the wake model and its physical behavior as compared with observations and CRM simulations. A similar exercise would be necessary for oceanic conditions. Thus, it is suggested that such a case be built, as the design of the TOGA maritime case appeared too specific to test intensively the coupled wake-convection model.

We hope that (after some testing) a single set of values will be sufficient to represent different regimes of convection in different parts of the world, if the shear dependency and a model of wake density are introduced.

Concerning the way the coupled scheme operates, the ALE/ALP closure proves to be an efficient way of representing the action of wakes on convection. This is an important point, since the ALE/ALP concept may be generalized to describe the action of other subcloud processes on convection. Recently, Rio et al. (2009) coupled this wake model with a PBL scheme through the use of the ALE/ALP approach and succeeded in simulating the diurnal cycle of convection for an ARM case. Also, the parameterization of ALE/ALP generated by orography is currently being developed. Conversely, the differential heating and drying induced by the saturated drafts and the unsaturated downdrafts of Emanuel's convection scheme appear capable of driving a density current parameterization.

To conclude, the coupled wake-convection scheme can simulate maritime convective systems with shallow wakes as well as continental ones with deep wakes. Its implementation in a GCM is underway. First results have been presented recently by R. Roehrig and J.-Y. Grandpeix (2009, unpublished manuscript). The scheme still contains very crude approximations that will need further work, such as the absence of differentiation of surface fluxes between the $(w)$ and $(x)$ regions. The most challenging prospect is to represent the propagation of density currents from grid cell to grid cell, a step that will open the way toward full description of the life cycle of convective systems in climate models.

Acknowledgments. This work emerged from the WAMP European project; it was pursued during the European project EUROCS and completed thanks to the AMMA project. Based on a French initiative, AMMA has been established by an international group and is currently funded by a large number of agencies, especially from France, the United Kingdom, and Africa. It has been the beneficiary of a major financial contribution from the European Community's Sixth Framework Research Programme. Detailed information on scientific coordination and funding is available on the AMMA international web site (http://www.amma-eu.org/). We thank again many colleagues at LMD and CNRMGAME (Frederic Hourdin, Catherine Rio, Romain Roehrig, etc.) for numerous discussions and comments throughout the development and the implementation of this new scheme, and Susan Becker for the English editing of the text. Thanks also to the anonymous reviewers and to the editor for their useful and pertinent comments.

\section{REFERENCES}

Bechtold, P., and Coauthors, 2000: A GCSS model intercomparison for a tropical squall line observed during TOGA COARE. II: Intercomparison of single-column models and a cloud-resolving model. Quart. J. Roy. Meteor. Soc., 126, 865-888.

Bryan, G., D. Ahijevych, C. Davis, S. Trier, and M. Weisman, 2005: Observations of cold pool properties in mesoscale convective systems during BAMEX. Preprints, 11th Conf. on Mesoscale Processes, Albuquerque, NM, Amer. Meteor. Soc., JP5J.12. [Available online at ams.confex.com/ams/pdfpapers/96718.pdf.]

Diongue, A., J.-L. Lafore, J.-L. Redelsperger, and R. Roca, 2002: Numerical study of a Sahelian synoptic weather system: Initiation and mature stages and its interactions with the large-scale dynamics. Quart. J. Roy. Meteor. Soc., 128, 1899-1927.

Emanuel, K. A., 1991: A scheme for representing cumulus convection in large-scale models. J. Atmos. Sci., 48, 2313-2335. 
1993: A cumulus representation based on the episodic mixing model: The importance of mixing and microphysics in predicting humidity. The Representation of Cumulus Convection in Numerical Models, Meteor. Monogr., No. 46, Amer. Meteor. Soc., 185-192.

Gaynor, J. G., and P. A. Mandics, 1978: Analysis of the tropical marine boundary layer during GATE using acoustic sounder data. Mon. Wea. Rev., 106, 223-232.

Goutorbe, J.-P., and Coauthors, 1994: HAPEX-Sahel: A largescale study of land-atmosphere interactions in the semi-arid tropics. Ann. Geophys., 12, 53-64.

Grandpeix, J.-Y., and J.-P. Lafore, 2010: A density current parameterization coupled with Emanuel's convection scheme. Part I: The models. J. Atmos. Sci., 67, 881-897.

Hourdin, F., and Coauthors, 2006: The LMDZ4 general circulation model: Climate performance and sensitivity to parametrized physics with emphasis on tropical convection. Climate Dyn., 27, 787-813.

Jorgensen, D. P., M. A. LeMone, and S. B. Trier, 1997: Structure and evolution of the 22 February 1993 TOGA COARE squall line: Observations of precipitation, circulation, and surface energy fluxes. J. Atmos. Sci., 54, 1961-1985.

Lafore, J.-P., J.-L. Redelsperger, and G. Jaubert, 1988: Comparison between a three-dimensional simulation and Doppler radar data of a tropical squall line: Transport of mass, momentum, heat, and moisture. J. Atmos. Sci., 45, 3483-3500.

, and Coauthors, 1998: The Méso-NH atmospheric simulation system. Part I: Adiabatic formulation and control simulations. Ann. Geophys., 16, 90-108.

Montmerle, T., and Y. Lemaitre, 1998: Three-dimensional variational data analysis to retrieve thermodynamical and dynamical fields from various nested wind measurements. J. Atmos. Oceanic Technol., 15, 360-379.
_ J.-P. Lafore, and J.-L. Redelsperger, 2000: A tropical squall line observed during TOGA COARE: Extended comparisons between simulations and Doppler radar data and the role of midlevel wind shear. Mon. Wea. Rev., 128, 3709-3730.

Piriou, J. M., J.-L. Redelsperger, J. F. Geleyn, J.-L. Lafore, and F. Guichard, 2007: An approach for convective parameterization with memory: Separating microphysics and transport in grid-scale equations. J. Atmos. Sci., 64, 4127-4139.

Qian, L., G. S. Young, and W. M. Frank, 1998: A convective wake parameterization scheme for use in general circulation models. Mon. Wea. Rev., 126, 456-469.

Redelsperger, J.-L., and Coauthors, 2000: A GCSS model intercomparison for a tropical squall line observed during TOGA COARE. I: Cloud-resolving models. Quart. J. Roy. Meteor Soc., 126, 823-863.

— A. Diongue, A. Diedhiou, J.-P. Ceron, M. Diop, J. F. Gueremy, and J.-P. Lafore, 2002: Multi-scale description of a Sahelian synoptic weather system representative of the West African monsoon. Quart. J. Roy. Meteor. Soc., 128, 1229-1257.

Rio, C., F. Hourdin, J.-Y. Grandpeix, and J.-P. Lafore, 2009: Shifting the diurnal cycle of parameterized deep convection over land. Geophys. Res. Lett., 36, L07809, doi:10.1029/ 2008 GL036779.

Rozbicki, J. J., G. Young, and L. Qian, 1999: Test of a convective wake parameterization in the single-column version of CCM3. Mon. Wea. Rev., 127, 1347-1361.

Yanai, M., S. Esbensen, and J.-H. Chu, 1973: Determination of bulk properties of tropical cloud clusters from large-scale heat and moisture budgets. J. Atmos. Sci., 30, 611-627.

Young, G. S., S. M. Perugini, and C. W. Fairall, 1995: Convective wakes in the equatorial western Pacific during TOGA. Mon. Wea. Rev., 123, 110-123. 